Maurício Olbrick Rodrigues

\title{
AVALIAÇÃO DA QUALIDADE DO TRANSPORTE COLETIVO DA CIDADE DE SÃO CARLOS
}

Dissertação apresentada a Escola de Engenharia de São Carlos, da Universidade de São Paulo, como parte dos requisitos para obtenção do título de Mestre em Engenharia de Transportes.

Orientador: Prof. Titular Antonio Clóvis Pinto Ferraz

São Carlos

2006 
Dedico este trabalho aos meus pais Adélcio e Genesi, a minha esposa Elisandra e a minha filha Julia. 


\section{Agradecimentos}

Agradeço a todos aqueles que contribuíram para a realização deste trabalho.

Ao professor Coca Ferraz, orientador da dissertação.

Aos diretores da Athenas Paulista: Dr. Miguel, Edison e Marco Aurélio.

Aos professores Eiji, José Leomar e Antônio Nélson, sendo este responsável pelo meu início na pesquisa acadêmica.

Ao amigo Hilário que, pelas discussões técnicas, agregou valor ao trabalho.

A minha sogra Catarina.

As funcionárias do departamento de Transportes Magali, Beth e Heloísa. 
O aspecto mais triste da vida de hoje é que a ciência ganha em conhecimento mais rapidamente que a sociedade em sabedoria.

Isaac Asimov 


\section{RESUMO}

RODRIGUES, M. O. (2006). Avaliação da qualidade do transporte coletivo da cidade de São Carlos. Dissertação (Mestrado) - Escola de Engenharia de São Carlos, Universidade de São Paulo.

Neste trabalho são apresentados os resultados de avaliação do transporte público urbano por ônibus na cidade de São Carlos, sob a ótica da qualidade dos serviços. O primeiro método de avaliação consistiu na aplicação de pesquisa aos usuários do sistema, onde foram avaliados o desempenho e a importância dos principais fatores de qualidade. A segunda forma de avaliação considerou a metodologia utilizada pela Prefeitura Municipal de São Carlos no acompanhamento do serviço prestado pela empresa operadora do transporte. No terceiro método foram entrevistados três especialistas que procederam a avaliação dos fatores considerando os padrões estabelecidos por Ferraz e Torres. Com base nessas avaliações, sobretudo nos resultados da pesquisa de opinião com os usuários, foram identificados os principais aspectos positivos e negativos do transporte coletivo. À luz desses fatos, é apresentado um conjunto de ações para melhoria do sistema. Essas ações, basicamente, se resumem no seguinte: regularizar o pavimento das vias por onde circulam os coletivos, melhorar a sinalização vertical e horizontal, instalar mais abrigos com bancos, disponibilizar informações das linhas e horários nos pontos de embarque, colocar maior quantidade de ônibus no horário de pico e fazer um reestudo no traçado das linhas atuais diminuindo o intervalo entre atendimento em alguns locais específicos.

Palavras chave: qualidade, transporte público urbano, ônibus, usuário. 


\section{ABSTRACT}

RODRIGUES, M. O. (2006). An evaluation of the level of service in the public transportation system of the city of São Carlos. Dissertation (Master) - School of Engineering of São Carlos, University of São Paulo.

The results of a three-step level of service evaluation of the public transportation service by bus in the city of São Carlos are presented in this work. The first evaluation was carried out directly with the system users through a field survey, in which the performance and the weights of the main level of service indicators were quantitatively measured. A second evaluation strategy made use of a methodology applied by the municipality of São Carlos to assess the quality of the service provided by the private bus operator. The third and final evaluation was based on quality standards specifically defined by Ferraz and Torres to assess the bus service in medium-sized cities. In that case, interviews with three experts were conducted. The analysis of the three evaluation methods provided elements to identify the main positive and negative aspects of the transit service in São Carlos and also suggestions for the system improvement. Those suggestions can be summarized as follows: improvement of street signs (vertical and horizontal), installation of more bus shelters with seats, up-to-date posting of transit routes and schedules at bus stops, more buses operating in peak periods, and redesign of the current routes for reducing the bus headways in specific areas of the city.

Key words: quality, urban public transportation, bus, users. 


\section{LISTA DE FIGURAS}

Figura 3.1 - Mapa do sistema viário de São Carlos ................................................ 36

Figura 3.2 - Mapa da rede de linhas de ônibus de São Carlos................................ 37

Figura 4.1 - Avaliação do desempenho dos fatores de qualidade...........................46

Figura 4.2 - Desempenho x Importância dos fatores de qualidade........................ 47

Figura 4.3 - Desempenho x Importância dos fatores de qualidade

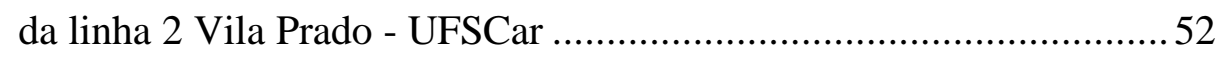

Figura 4.4 - Desempenho x Importância dos fatores de qualidade para o segmento "trabalhador" 54 


\section{LISTA DE TABELAS}

Tabela 1.1 - Mapa da frota atual de São Carlos................................................... 4

Tabela 1.2 - Índices de motorização ............................................................. 5

Tabela 2.1 - Duas visões da qualidade ......................................................... 11

Tabela 2.2 - Padrões de qualidade para o transporte público por ônibus................. 24

Tabela 2.3 - Pesos considerados para períodos e tipos de dia ................................26

Tabela 2.4 - Valores para os indicadores e as notas associadas ............................. 32

Tabela 3.1 - Relação das linhas regulares ....................................................... 38

Tabela 4.1 - Porcentagem de usuários referente a cada linha e

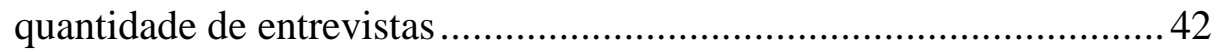

Tabela 4.2 - Quantidade de usuários pesquisados por categoria .......................... 43

Tabela 4.3 - Importância dos fatores de qualidade ............................................ 44

Tabela 4.4 - Desempenho dos fatores de qualidade............................................ 45

Tabela 4.5 - Resultado da avaliação dos indicadores ........................................ 48

Tabela 4.6 - Resultado da avaliação dos indicadores do $2^{\circ}$ semestre .................... 49

Tabela 4.7 - Avaliação técnica da qualidade .......................................................50

Tabela 4.8 - Resumo dos resultados para a linha 2 Vila Prado - UFSCar ...............51

Tabela 4.9 - Resumo dos resultados para o segmento "trabalhador" .....................53 


\title{
LISTA DE SÍMBOLOS
}

\author{
$N_{j} \quad$ Nota atribuída ao indicador $\mathrm{j}$ \\ $\operatorname{Vmax}_{j} \quad$ Valor máximo atribuído ao indicador $\mathrm{j}$ \\ $\operatorname{Vmin}_{j} \quad$ Valor mínimo atribuído ao indicador $\mathrm{j}$ \\ Vmed $_{j} \quad$ Valor apurado do indicador $\mathrm{j}$ \\ $Q T C_{k} \quad$ Índice de qualidade do serviço de transporte no período k \\ $\mathrm{Peso}_{j} \quad$ Peso do indicador j
}




\section{SUMÁRIO}

1. INTRODUÇÃ

1.1 Considerações gerais ................................................................ 1

1.2 Objetivos do trabalho ................................................................ 4

1.3 Importância do trabalho ............................................................... 4

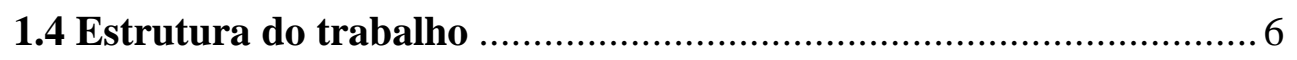

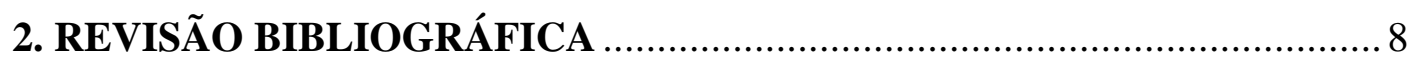

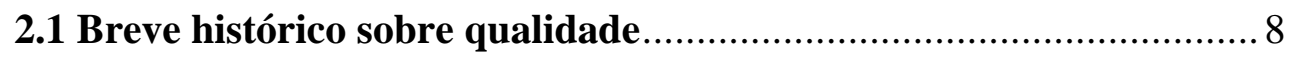

2.2 Conceito de qualidade na prestação de serviços................................ 11

2.3 Qualidade no transporte coletivo ....................................................... 14

2.4 Padrões de qualidade para o transporte público por ônibus.............24

2.5 Método de avaliação da qualidade adotado pela Prefeitura

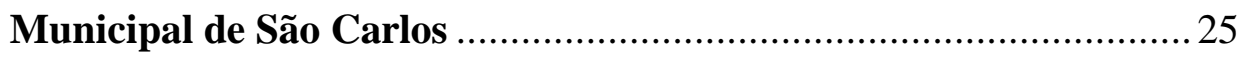

2.6 Pesquisas de opinião em transporte coletivo ……………………...... 33

3. O SISTEMA DE TRANSPORTE COLETIVO DE SÃO CARLOS ...............35

4. DIAGNÓSTICO SOBRE A QUALIDADE DO SERVIÇO ............................ 41

4.1 Avaliação baseada em entrevistas realizadas com usuários .............. 41

4.2 Avaliação realizada pela Prefeitura Municipal ................................. 48

4.3 Avaliação subjetiva realizada por técnicos.......................................50

4.4 Análises desagregadas da pesquisa de opinião ………………….......51

5. CONCLUSÕES 


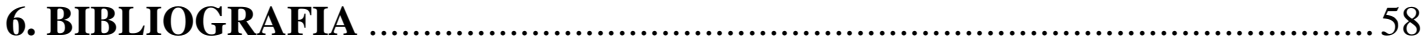

7. APÊNDICES 


\section{INTRODUÇÃO}

\subsection{Considerações gerais}

O transporte coletivo urbano por ônibus é um importante e necessário meio de integração entre as diversas áreas econômicas e sociais dos centros urbanos, desempenhando importante papel no desenvolvimento industrial, na expansão do comércio, nos programas de saúde, na educação, entre outras atividades.

O transporte público coletivo urbano tem como objetivo fazer a ligação entre as diversas regiões de uma cidade, proporcionando, assim, mobilidade motorizada aqueles que não podem ou não querem utilizar um veículo particular.

O transporte coletivo tem importância fundamental dentro do contexto geral do transporte urbano, na medida em que é essencial para a população de baixa renda e, ao mesmo tempo, uma importante alternativa a ser utilizada como estratégia para redução das viagens por automóvel, contribuindo para a redução dos congestionamentos, da poluição ambiental, dos acidentes de trânsito e do consumo de combustível.

Configurada a relevância do transporte público urbano espera-se que os métodos e procedimentos desenvolvidos para auxiliar no seu planejamento e avaliação sejam amplamente utilizados e constantemente aperfeiçoados. 
É preciso que sejam definidos padrões de serviço aceitáveis para efeito de planejamento, que satisfaçam à maioria dos usuários habituais do sistema de transporte coletivo urbano, constituído na maior parte de pessoas oriundas de classes menos favorecidas. Vale dizer, no entanto, que esses padrões variam de país para país, e até mesmo em função do porte da cidade. (FERRAZ, 1998).

No setor de transportes, a qualidade, quase sempre, tem sido vista mais como um condicionante a ser atingido na busca de redução de custos do que uma meta a ser alcançada ou superada tendo em conta a necessidade de sobrevivência das empresas, em virtude da estrutura de mercado vigente.

Essa visão faz com que o usuário não seja definido nem como consumidor, nem como cidadão, ou seja, o sistema não funciona nem de acordo com as leis de mercado nem tampouco como um serviço público essencial à cidade, voltado aos interesses e necessidades da população. Assim, os responsáveis pelo transporte urbano, na ótica dos usuários, têm objetivos contrários aos da população. De um lado, as empresas de transporte e o poder municipal, e do outro, os clientes desatendidos, como se houvesse um tipo de associação entre os setores privado e estatal contrário aos interesses dos usuários.

Segundo VASCONCELLOS (1996), as recentes mudanças na ordem política e econômica, não só no Brasil, mas no mundo, mostram que não se deve deixar de olhar o transporte coletivo sob a lógica do mercado, mas é preciso que ele também seja tratado como serviço público de caráter universal. Portanto, a tentativa de manter os subsídios no nível mínimo, caso da operação pública, ou de manter a rentabilidade no nível máximo, caso da operação privada, estão ambos em conflito direto com o interesse dos usuários, uma vez que elas forçam uma redução no nível da oferta e da qualidade do serviço.

Nos sistemas de transportes públicos, de modo geral, uma nova postura se faz cada vez mais necessária: a preocupação com o usuário e com seus anseios. Está ultrapassado o conceito tradicionalmente estabelecido pela empresa prestadora do transporte que a define como a relação entre o serviço planejado e o serviço oferecido, sendo que o mais 
correto seria a visão com foco no usuário e definida como o serviço recebido em relação ao serviço almejado.

Ultimamente, tem-se observado uma crescente busca de qualidade pelo consumidor de produtos e serviços. Regulamentações, como o Código de Defesa do Consumidor, têm contribuído para garantir o direito de exigir qualidade em tudo que é comercializado. Uma parte dos clientes está se tornando hoje mais crítica em relação aos serviços que recebem. Um número significativo de clientes está não somente desejando, mas esperando melhores serviços e com qualidade. A ferramenta mais visível de percepção da qualidade é o serviço prestado ao cliente.

Ao significado atual da palavra qualidade estão associados a valorização da visão do cliente, a gestão dos processos, e a motivação das pessoas para a melhoria contínua e para a busca da excelência. Contudo, até agora o que se desenvolveu na área de transportes e foi denominado como qualidade teve o enfoque do processo de produção dos serviços, enfatizando as medidas técnicas e a conformidade às especificações, e pouca ênfase foi dada em relação à satisfação dos usuários e a motivação dos empregados.

O ideal seria adotar uma estratégia operacional que permita alcançar a excelência na prestação desse tipo de serviço. Esta estratégia pode ser traduzida por uma gestão que possibilite obter, uma vez conhecidas as necessidades do cliente e as especificações do serviço a ser oferecido, a máxima eficiência do mesmo tendo em conta um determinado nível de serviço esperado pelo cliente, ou seja, deve-se desenvolver um processo que permita tratar simultaneamente a produtividade e a qualidade de um sistema de transporte público urbano onde seja possível maximizar a produtividade da empresa, atendendo, porém, as restrições de qualidade do serviço vistas sob a ótica do cliente.

A atividade de transportes não tem como resultado de sua produção bens físicos tangíveis, na verdade o que se faz é agregar benefícios aos passageiros em termos de utilidade de tempo e de espaço. A importância do transporte no cotidiano das pessoas fica evidenciada pelo tempo, cada vez maior, gasto nos deslocamentos diários entre o local de moradia e de trabalho. 


\subsection{Objetivos do trabalho}

O presente trabalho tem como objetivos:

- Realizar um diagnóstico sobre a qualidade do sistema de transporte coletivo urbano da cidade de São Carlos.

- Propor ações em nível estratégico para a melhoria da qualidade do serviço à luz do diagnóstico.

O diagnóstico foi realizado com base nas seguintes informações:

- Resultados fornecidos pelo método de avaliação adotado pela Prefeitura Municipal, em duas pesquisas realizadas nos anos de 2004 e 2005.

- Resultados obtidos em pesquisa de opinião realizada em 2005 com três especialistas, tomando como referência os padrões estabelecidos por Ferraz e Torres (2004).

- Resultados obtidos em pesquisa de opinião dos usuários, realizada em 2005.

\subsection{Importância do trabalho}

A população estimada do município de São Carlos é de 209.009 habitantes, segundo PREFEITURA MUNICIPAL DE SÃO CARLOS (2005), e a frota veicular, conforme mostrado na tabela 1.1 , é de 94.183 veículos. Assim, o índice de motorização no município é de 45 veículos/100 habitantes.

Tabela 1.1 - Mapa da frota atual de São Carlos. Fonte: PRODESP (2005).

\begin{tabular}{cc}
\hline TIPO & QUANTIDADE \\
\hline Automóvel & 65537 \\
Caminhão & 3062 \\
Camioneta & 6806 \\
Microônibus & 220 \\
Motocicleta & 14594 \\
Ônibus & 291 \\
Outros & 3673 \\
Total & 94183
\end{tabular}


A tabela 1.2 apresenta os índices de motorização de alguns países, onde se pode observar que a taxa de São Carlos é muito próxima a de alguns países europeus, que apresentam um índice elevado de veículos por habitante.

Tabela 1.2 - Índices de motorização. Fonte: VUCHIC (2000).

\begin{tabular}{lc}
\hline \multicolumn{1}{c}{ País } & Veículos por 100 habitantes \\
\hline Cuba e Índia & $<10$ \\
Grécia & $10-20$ \\
Portugal & $20-30$ \\
Dinamarca, Espanha, Holanda, Noruega e Finlândia & $30-40$ \\
Bélgica, Inglaterra, Áustria, França, Suécia e Austrália & $40-50$ \\
Itália e Estados Unidos & $>50$ \\
\hline
\end{tabular}

O elevado índice de motorização existente na cidade de São Carlos leva a um grande número de viagens de automóvel por habitante e esse fato acaba refletindo negativamente no transporte público por ônibus pois, com algumas exceções, como a faixa exclusiva para coletivos, os dois tipos de veículos sempre utilizam o mesmo espaço viário.

Segundo LIMA JR. (1995), os custos da falta de qualidade no caso de transportes são em muitas situações altos para a sociedade devido aos congestionamentos, acidentes, avarias e mortes. Muitas vezes estes custos não são bem identificados ou desconsiderados por dificuldades associadas às formas de quantificar tempos perdidos e avarias e por os mesmos não incidirem diretamente no prestador do serviço, diferente dos retrabalhos e desperdícios de insumos associados ao processo produtivo.

Dessa forma, faz-se necessário reavaliar o modelo de transporte e trânsito da cidade, afim de que seja garantida uma melhor distribuição de deslocamento, ao lado de uma maior eficiência. Esta última pode ser obtida se o processo de desenvolvimento urbano e as políticas de transporte forem revistas, forçando um equilíbrio entre os modos que otimize a produtividade do sistema e promova condições adequadas para os usuários. 
Tais políticas devem ser adotadas de forma a garantir:

- Melhor qualidade de vida para a população da cidade;

- Eficiência da infra-estrutura e dos serviços públicos da cidade;

- Minimização dos impactos ambientais.

Em vista do exposto, o presente trabalho deve cumprir a sua finalidade acadêmica e, ao mesmo tempo, ser útil para a Prefeitura da cidade de São Carlos no sentido de formar subsídios visando à melhoria do sistema de transporte coletivo urbano.

\subsection{Estrutura do trabalho}

O trabalho encontra-se estruturado da maneira colocada a seguir.

No capítulo 1 são apresentadas as considerações introdutórias e colocados os objetivos e a importância do trabalho.

No capítulo 2 são discutidos alguns aspectos sobre qualidade, tanto a sua evolução histórica como a diferenciação entre qualidade de um produto e qualidade na prestação de serviços. Definem-se ainda os fatores de qualidade considerados pelos usuários e a metodologia de avaliação utilizada atualmente pela Prefeitura Municipal.

O capítulo 3 contém uma descrição do sistema de transporte público urbano existente na cidade de São Carlos.

O capítulo 4 apresenta os resultados da pesquisa realizada em Outubro de 2005 com os usuários do transporte coletivo, da avaliação realizada pela Prefeitura Municipal em 2004/2005 e da pesquisa de opinião com três especialistas no assunto, bem como o diagnóstico.

No capítulo 5 são propostas ações para melhorar os fatores de qualidade que não foram bem avaliados e são feitas algumas colocações finais consideradas relevantes. 
O capítulo 6 contém a bibliografia consultada no desenvolvimento do trabalho. 


\section{REVISÃO BIBLIOGRÁFICA}

\subsection{Breve histórico sobre qualidade}

Até o período que antecede a Revolução Industrial, a qualidade pode ser entendida como uma atividade de autocontrole realizada pelos artesãos, pois desenvolviam todas as etapas, tais como concepção, escolha de materiais, produção e comercialização direta com os clientes. A produção era pequena e a inspeção após o produto pronto era informal. Nesta fase o conceito de qualidade é sinônimo de perfeição técnica.

Segundo BRASSARD (1985) no início do Século XX, com a produção em massa e o surgimento das teorias de Administração Científica da Produção, a prática do controle da qualidade mudou e passou a ser atividade externa à produção, ou seja, foi vista como responsabilidade gerencial distinta e como função independente. A inspeção tinha por objetivo separar os produtos bons dos defeituosos, antes de serem expedidos ao consumidor, e garantir a intercambialidade das peças.

No final da década de 20 surgiram as Cartas de Controle de Processo que levaram a identificação de dois tipos básicos de causas de variabilidade da resposta, parâmetro de qualidade, de um processo: as causas inerentes ao processo, assim como foi projetado, e as causas esporádicas que levam a um aumento transitório da variabilidade do processo. 
No final da década de 30, surgiram novas técnicas para a inspeção de lotes de produtos por amostragem, baseadas na abordagem probabilística para a previsão da qualidade do lote a partir da qualidade da amostra. Um dos produtos dessa teoria é o conceito de Nível de Qualidade Aceitável, onde existe uma meta em termos de porcentagem de defeituosos, baseada em razões econômicas.

No período entre as décadas de 20 e 50, enquanto as técnicas de controle de qualidade evoluíram para o controle estatístico da qualidade do processo, em termos conceituais a qualidade evoluiu de perfeição técnica para nível aceitável de qualidade.

A partir da década de 50, o conceito de qualidade foi revisto, com a introdução dos conceitos de Qualidade Total por pioneiros como W. E. Deming, J. M. Juran, A. V. Feigenbaum e outros.

W. E. Deming conseguiu perceber a importância, para o bom uso das ferramentas estatísticas de controle da qualidade, do comprometimento de longo prazo da alta administração para o objetivo de melhorias contínuas da qualidade, assim como investimento em treinamento, educação de recursos humanos e mudanças nos métodos gerenciais.

Armand Feigenbaum explicava que produtos de alta qualidade não teriam chance de serem produzidos se o departamento de fabricação continuasse a trabalhar isoladamente. O princípio em que se assenta esta visão de qualidade total é que, para se conseguir uma verdadeira eficácia, o controle precisa começar pelo projeto do produto e só terminar quando o produto tiver chegado as mãos do freguês, ou seja, qualidade é um trabalho de todos.

Nota-se uma nova mudança no conceito de qualidade, aproximando-a mais da satisfação do consumidor e distanciando-se da visão de nível aceitável de qualidade.

Na década de 70, Philip B. Crosby introduziu o conceito de qualidade na administração e foi um dos idealizadores do programa Zero Defeito. Ele constatou que os defeitos eram, em sua maioria, um problema de atitude, ou seja, a falta de perfeição existia 
porque ninguém esperava a perfeição. Uma vez estando os empregados imbuídos de um ideal, motivados e treinados, a meta Zero Defeito era possível.

G. Taguchi propôs o uso da Função Perda de Qualidade para avaliar os custos por não ter qualidade e definiu qualidade como a perda mensurável e não mensurável que um produto impõe à sociedade após o seu despacho.

Segundo CAMPOS (1992), a filosofia de Qualidade Total levou, durante as últimas décadas, ao surgimento de programas de Gestão da Qualidade Total, que é um sistema ou conjunto de atividades cujo objetivo é identificar e administrar as atividades necessárias para a maximização da competitividade de uma empresa através da melhoria contínua da qualidade de seus produtos, serviços, processos e recursos humanos, e conseqüente redução de custos.

A Gestão da Qualidade Total se fundamenta em alguns princípios que são:

- Satisfação total do cliente;

- Compromisso da alta administração com a qualidade e constância de propósitos;

- Desenvolvimento de recursos humanos, educação, treinamento e delegação de responsabilidade;

- Gerência participativa e por processos;

- Garantia de qualidade e aperfeiçoamento contínuo de produtos e processos;

- Uso de metodologias científicas;

- Disseminação e padronização da informação.

A Tabela 2.1 apresenta uma comparação entre a visão tradicional e a nova visão da qualidade. 
Tabela 2.1 - Duas visões da qualidade. Fonte: BROCKA \& BROCKA (1994)

Visão Tradicional

Nova Visão

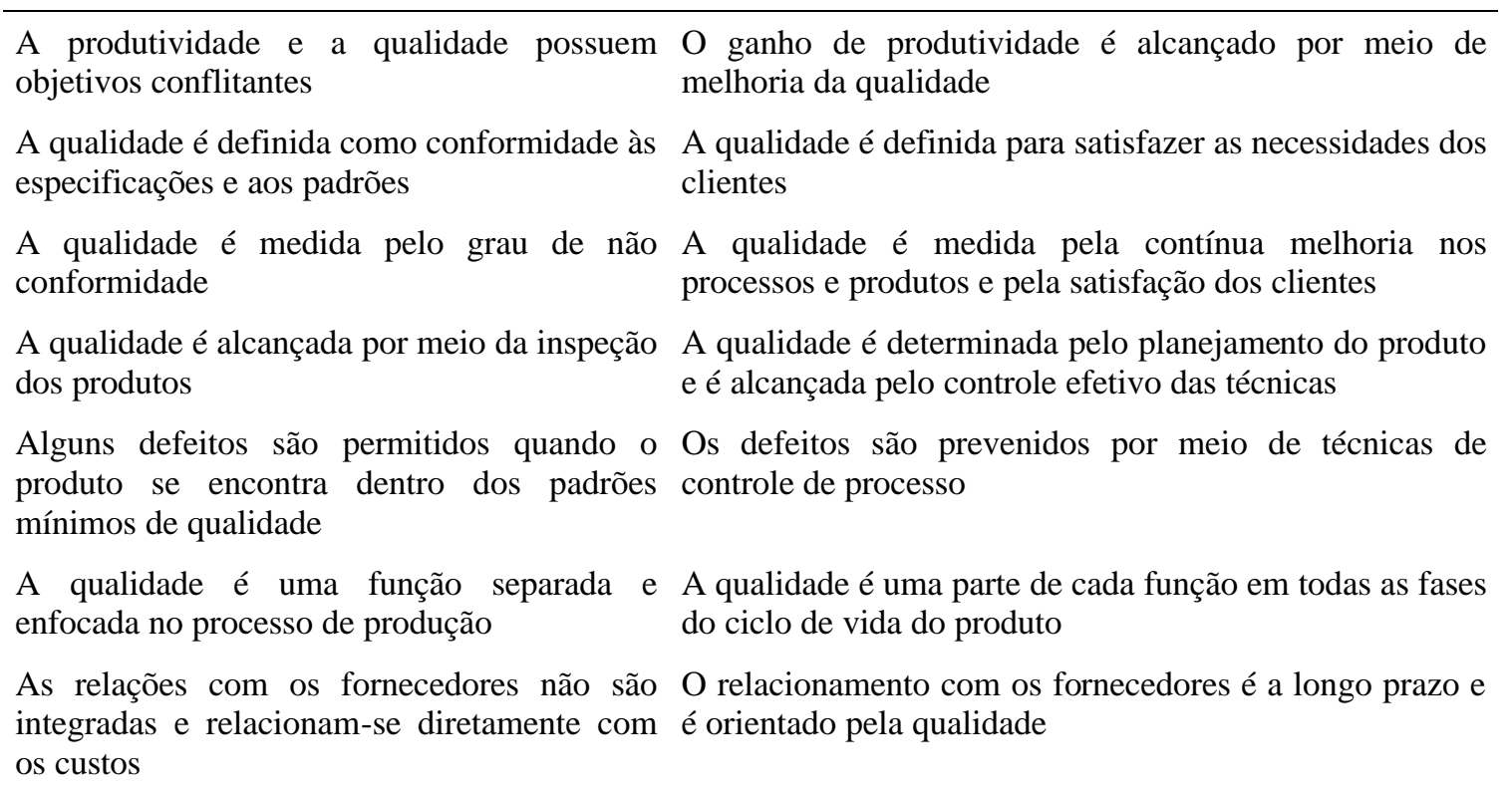

O sistema de Gestão da Qualidade Total e os Programas de Qualidade tradicionalmente têm sido implementados por intermédio das normas internacionais ISO - International Standard Organization - da série ISO 9000, e, principalmente, pelos critérios de avaliação do Prêmio Malcolm Baldrige, que no Brasil se materializou pela criação do Prêmio Nacional de Qualidade. Há um conjunto de regras e procedimentos que têm a finalidade de orientar a organização, no sentido de garantir as condições básicas para o sucesso do empreendimento.

\subsection{Conceito de qualidade na prestação de serviços}

Existem significativas diferenças na implantação de programas de Qualidade entre as organizações de bens e as de serviços. Conseguir fatos e dados em uma empresa tipicamente de bens é diferente de conseguí-los em uma de serviços.

Alguns engenheiros afirmam que não existem serviços, somente produtos. O contrário também pode ser propalado por administradores.

Um produto é tudo aquilo que está no final de um processo de elaboração e pronto para ser comercializado ou ofertado. Assim, um produto pode ser um bem ou serviço. 
Existem produtos que tem características preponderantemente materiais, enquanto outros são completamente intangíveis.

O serviço é uma atividade ou uma série de atividades de natureza intangível, que normalmente acontece durante as interações entre clientes e empregados de serviço e/ou recursos físicos ou bens e/ou sistemas do fornecedor de serviços, que é apresentada como solução ao problema do cliente.

Segundo TRAVASSOS (2005), no transporte público por ônibus o cliente não recebe qualquer resultado material do serviço prestado, no entanto, este setor não poderia ser caracterizado como um serviço puro que envolvesse apenas os recursos humanos, uma vez que para sua prestação, faz-se necessário o uso de equipamentos razoavelmente sofisticados, os ônibus.

Além disso, o setor sofre influência de outros serviços que extrapolam a possibilidade de atuação do operador de transporte, tais como:

- Gestão do trânsito;

- Conservação do sistema viário;

- Manutenção da segurança pública.

A imagem do produto tangível pesa mais na formação das expectativas do consumidor do que qualquer afirmativa exagerada do anunciante de um serviço, isso significa que por melhor que seja a propaganda sobre determinado bem, quando o cliente estiver diante dele será o teste final, a despeito de uma expectativa anterior. Com o serviço, por não haver a avaliação do aspecto de tangibilidade, o grupo de expectativas detêm a parte mais importante do processo de compra.

Segundo LIMA JR. (1995), o principal aspecto que amplia a abordagem da qualidade em serviços é a valorização da função e do benefício gerado em detrimento das características físicas dos produtos, que passam a serem facilitadores da execução da função. 
Se se entender produção de serviços como comportamento ou atividade humana aliada a objetos e processos específicos cujo objetivo é ajudar clientes a encontrar o imediato e contínuo atendimento de suas necessidades, então este comportamento ou atitude pode ser medido ou observado, contrariando a hipótese de que qualidade na prestação de serviços é intangível.

Podem ser identificados outros aspectos que se aplicam ao serviço de transporte público urbano por ônibus e o tornam bastante peculiar, são eles:

- Intangibilidade - o bem adquirido não pode ser previamente visto, sentido, tocado ou provado.

- Inseparabilidade - a produção e o consumo ocorrem simultaneamente.

- Variabilidade - é uma atividade de difícil padronização, pois cada viagem ocorre em circunstâncias singulares, quer pelas condições do tráfego, do clima, do horário, do dia, da quantidade e do tipo de usuários transportados, ou seja, cada viagem é um produto único e diferenciado.

- Perecibilidade - o serviço não pode ser estocado; uma vez oferecido e não consumido, perde-se.

- Consumo intensivo - trata-se de um bem consumido diariamente, pelo menos duas vezes ao dia.

- Consumo coletivo - ao contrário de outros serviços, onde o consumo se dá individualmente com tratamento personalizado, no transporte o consumo ocorre de forma massificada e em grupos nem sempre homogêneos.

- Pagamento antecipado - na maioria das vezes implica em pagamento antes da prestação do serviço.

- Interação com o meio ambiente - o serviço é realizado em ambientes não controlados, ao contrário da manufatura, por exemplo.

- Atuação dispersa espacialmente - a operação é bastante dispersa, o que dificulta significativamente a supervisão do serviço e o controle do pessoal.

- Mercados fortemente regulamentados - a rigidez das regulamentações praticadas inibe que o serviço seja prestado em condições mais adequadas às necessidades dos clientes.

- Satisfação com o resultado e com o processo - neste serviço o cliente deseja além da satisfação com o resultado, a satisfação na participação do processo, ou seja, ele 
quer chegar ao local e no horário programado e que isto ocorra com segurança e razoável conforto.

A qualidade do serviço, corretamente entendida, pode se transformar em uma força altamente efetiva, um meio de se criar e sustentar uma vantagem competitiva, entendendo-se por esta como a diferença perceptível de satisfazer melhor que os concorrentes as necessidades identificadas do cliente. Isso só pode acontecer se os serviços forem tratados como uma questão estratégica e forem acionados mecanismos para torná-los um valor-chave da organização.

Apesar dos clientes serem de fundamental importância para as organizações, poucas empresas parecem dispostas a fazer com que seu desempenho atenda as necessidades destes. A capacidade de satisfazer os desejos do cliente depende da clara compreensão de suas necessidades e atitudes em relação ao serviço.

O consumidor deve deixar de ser visto apenas como comprador e passar a ser considerado como um elemento portador de direitos que expressa opiniões e valores, os quais interferem na imagem da empresa.

Após a caracterização do serviço de transporte urbano, o foco estará no cliente, uma vez que este é a parte mais importante dessa atividade.

\subsection{Qualidade no transporte coletivo}

A realização de uma viagem por transporte coletivo urbano compõe-se das seguintes etapas: percurso a pé da origem até o local do embarque no sistema, espera pelo coletivo, deslocamento dentro do coletivo e caminhada do ponto de desembarque até o destino final. Muitas vezes também é necessário uma ou mais transferências entre coletivos para se atingir o destino almejado.

O transporte de pessoas, em geral, é uma atividade intermediária, e um serviço com qualidade oferece pequena impedância aos passageiros isto é, rapidez, conforto, 
segurança devem estar presentes em todas as etapas, minimizando os gastos de energia e tempo dos usuários.

A qualidade de um serviço pode ser avaliada através de indicadores. Exige-se, entre outros aspectos, que os indicadores de produtividade e qualidade sejam de formulação simples, possíveis de entendimento por todos os empregados envolvidos no processo de produção. Além disso, eles terão de apresentar um grau satisfatório de cobertura e representatividade das atividades e resultados gerados. (TIRONI et al, 1991).

Segundo WAISMAN (1983), a seleção de indicadores pode ser feita de acordo com um conjunto de sete critérios, que são:

- Comparabilidade - os indicadores devem permitir comparação entre diferentes áreas urbanas;

- Cobertura - a extensão em que o indicador reflete os vários aspectos da qualidade dos serviços;

- Resposta à necessidade - o grau pelo qual o indicador reflete a resposta do transporte coletivo às necessidades e demandas da área urbana;

- Compreensibilidade - a facilidade pelo qual o indicador pode ser entendido, não somente por técnicos, mas também administradores do transporte, políticos e outros grupos interessados;

- Flexibilidade - a facilidade e velocidade com que as características medidas pelos indicadores podem ser alteradas para satisfazer condições e necessidades de modificações;

- Incentivos para o alcance de melhorias - o grau pelo qual o uso do indicador poderá estimular a contínua busca de técnicas operacionais mais eficientes;

- Disponibilidade de dados - a extensão pelo qual o indicador depende de dados que são facilmente disponíveis e confiáveis, ou depende de dados que requerem estudos especiais, custosos e sujeitos a substancial margem de erro.

De acordo com FERRAZ \& TORRES (2004), são doze os fatores que influem na qualidade do transporte público urbano: acessibilidade, frequiência de atendimento, tempo de viagem, lotação, confiabilidade, segurança, características dos veículos, 
características dos locais de parada, sistema de informações, conectividade, comportamento dos operadores e estado das vias.

Na seqüência é apresentada a caracterização de cada um deles.

\section{Acessibilidade}

A acessibilidade é a distância percorrida para iniciar e finalizar a viagem por transporte público, sendo influenciada pelas características do percurso como declividade, existência ou não de calçamento nos passeios, estado das calçadas e facilidade para cruzar as ruas existentes no trajeto.

Segundo AGUIAR (1985), um item que reflete a acessibilidade do sistema de transporte é o número de estações ou pontos de embarque e desembarque, uma vez que quanto maior for esse número maior será a área coberta pelos serviços de transporte, levando-se em conta que cada ponto possui a sua área de influência própria.

\section{Freqüência de atendimento}

A frequiência de atendimento é o intervalo de tempo entre a passagem de dois veículos consecutivos de transporte público numa mesma linha e sentido.

Segundo FARIA (1985), os sistemas de ônibus com tempo médio de espera excessivo são indesejáveis, produzem atitudes desfavoráveis, uma vez que o tempo de espera é considerado ser mais desagradável. Caso este tempo fosse parcialmente economizado e ocupado com outra atividade psicologicamente mais conveniente, produziria uma atitude mais favorável com relação ao ônibus.

KAWAMOTO (1984) cita que a freqüência de atendimento é um dos elementos mais importantes do nível de serviço, uma vez que reflete o volume de serviço ofertado por unidade de tempo e provoca impactos em diversos aspectos. Um desses impactos é o tempo médio de espera dos usuários nos pontos de parada, pois considerando-se que a 
chegada seja aleatória - usuários não estão informados acerca do horário - o tempo médio de espera é a metade do headway, portanto intervalos menores tem como conseqüência tempo médio de espera satisfatórios.

\section{Tempo de viagem}

O tempo de viagem é o tempo gasto no interior dos veículos e depende da velocidade média de transporte e da distância entre os pontos de embarque e desembarque do sistema.

A velocidade de transporte depende do grau de separação da via utilizada pelo transporte público do tráfego geral, da distância dos locais de parada, das condições da superfície de rolamento, das condições do trânsito e do tipo de tecnologia dos veículos.

De acordo com FARIA (1985), a maioria dos usuários de transporte público considera o tempo de deslocamento como o fator mais importante de uma viagem, sob a ótica da qualidade, especialmente nas viagens pendulares, devido ao horário de entrada no trabalho.

Para avaliar a qualidade em relação ao tempo de viagem pode-se comparar o tempo de viagem do transporte público e o tempo gasto por automóvel, considerando os dois sentidos de viagem.

Segundo KAWAMOTO (1984), a duração da viagem em si não significa muito, o mais significativo é a duração em relação às modalidades alternativas, uma vez que os usuários comparam intuitivamente com elas. Esse fato permite estudar a capacidade do transporte público em competir com o transporte privado.

\section{Lotação}

Lotação é o número de passageiros no interior dos veículos, e o problema surge quando a quantidade de pessoas em pé é excessiva, devido ao desconforto decorrente da 
proximidade entre os usuários e a limitação de movimentos, que dificulta as operações de embarque e desembarque.

A densidade de passageiros encontrada nos transportes coletivos urbanos reflete, em parte, o nível de serviço do sistema, onde veículos lotados demonstram a incapacidade do sistema em atender a demanda.

A avaliação do fator lotação pode ser feita com base na taxa de pessoas em pé por metro quadrado que ocupam o espaço livre no interior dos veículos.

\section{Confiabilidade}

A confiabilidade é o grau de certeza dos usuários de que o veículo de transporte público vai passar na origem e chegar ao destino no horário previsto, considerando uma margem de tolerância.

A confiabilidade pode ser mais bem definida com os conceitos de pontualidade e efetividade. A pontualidade consiste no cumprimento dos horários estipulados no itinerário, sendo relevante para sistemas com baixa frequiência. A efetividade é a realização da programação operacional, ou seja, porcentagem das viagens realizadas em relação as viagens programadas.

A avaliação da confiabilidade se dá pela comparação do número de viagens não realizadas ou concluídas com atraso superior a cinco minutos ou adiantamento maior que três minutos por número total de viagens.

\section{Segurança}

A segurança compreende os acidentes envolvendo os veículos de transporte público e os incidentes como agressões e roubos no interior dos ônibus. 
Acidente de trânsito é todo e qualquer abalroamento, colisão, capotamento, tombamento, atropelamento, incêndio e qualquer outro sinistro precedido por um ato ou condição insegura que produz prejuízos e resultados irreversíveis.

Incidente de trânsito: qualquer fato acontecido isolado, não previsto, envolvendo veículos, operadores e passageiros, desde que não seja um acidente de trânsito, podendo vir a causar ou não perturbação na operação normal, gerando em alguns casos danos materiais e pessoais.

O fator segurança pode ser avaliado pelo número de acidentes/incidentes ocorridos em relação a uma determinada quilometragem percorrida, $100.000 \mathrm{~km}$ por exemplo.

\section{Características dos veículos}

Segundo EBTU (1986), as seguintes características dos veículos influem no conforto dos usuários: temperatura interna, ventilação, ruído, aceleração/desaceleração, altura dos degraus, largura das portas e disposição e material dos assentos.

Os degraus dos ônibus urbanos quase sempre são altos, causando desconforto, sobretudo a pessoas muito baixas, idosos, enfermos e crianças.

A maioria dos veículos conta somente com duas portas, o que dificulta a circulação dos passageiros pelo interior do ônibus, quando este apresenta níveis maiores de lotação. $\mathrm{O}$ aumento na largura das portas possibilita a passagem de duas pessoas por vez, facilitando os embarques e desembarques.

Quanto ao material dos assentos, grande parte dos ônibus tem bancos rígidos ou de fibra, sendo o mesmo recurso adotado em outros países. Porém, no exterior os veículos têm suspensão a ar e rodam por vias com pavimento liso, ao contrário do Brasil, onde predomina a suspensão mecânica e os veículos circulam por ruas esburacadas ou com pavimento irregular, fatos que trazem desconforto aos passageiros. 
No caso dos ônibus, a qualidade do parâmetro características dos veículos pode ser avaliada com base nos seguintes itens: idade, número de portas, largura do corredor e altura dos degraus das escadas e estado de conservação.

\section{Características dos locais de parada}

A relação cliente-fornecedor inicia-se a partir dos próprios pontos de parada ou terminais, que devem estar adequados para prover as necessidades básicas de conforto, informação e proteção aos usuários. Nos locais de parada, são importantes os seguintes aspectos: sinalização adequada e existência de cobertura e de bancos para sentar.

Nas regiões centrais a falta de sinalização horizontal e vertical faz com que outros veículos estacionem nos pontos de embarque e desembarque e os ônibus são obrigados a parar distante do meio fio, o que dificulta o acesso das pessoas idosas, atrasando a operação, além de impedir o fluxo de veículos por aquela faixa.

Algumas cidades, no período noturno, liberam a parada nos pontos regulamentados e deixam os usuários nos locais que julgam mais seguros ou próximos de suas residências.

A cobertura protege os usuários do sol e da chuva e os bancos trazem mais conforto, principalmente às pessoas idosas, crianças, enfermos, deficientes e mulheres grávidas.

A avaliação das características dos locais de parada leva em conta a presença de sinalização adequada, cobertura e bancos para sentar.

\section{Sistema de informações}

Como os sistemas de transporte coletivo são utilizados não somente pelos usuários habituais, é importante que as pessoas da própria cidade ou de fora, que fazem uso eventual do sistema, possam entendê-lo e utilizá-lo sem dificuldades. Para isso, é necessário que os itinerários das linhas sejam fáceis de memorizar, sem excesso de 
sinuosidades e passem nas vias principais de acesso e que o transporte conte com um sistema de informações adequado.

O sistema de informações aos usuários envolve os seguintes pontos: disponibilidade de folhetos com os horários e os itinerários das linhas, existência de informações sobre as linhas e os horários nos locais de parada, informações sobre a rede de linhas no interior dos veículos, fornecimento de informações verbais por parte de motoristas e cobradores, posto para fornecimento de informações e recebimento de reclamações e sugestões, pessoalmente e por telefone.

A avaliação do sistema de informações leva em conta a presença dos folhetos com linhas e horários e da existência de posto de atendimento aos usuários.

\section{Conectividade}

A conectividade é caracterizada pelo grau de facilidade de deslocamento dos usuários entre dois pontos quaisquer da cidade, ou seja, a porcentagem de viagens em transporte público urbano que não necessita de transferências e pelas características dos transbordos realizados.

$\mathrm{O}$ ideal seria que as viagens entre dois locais da cidade pudessem ser diretas, sem necessidade de trocar de ônibus, mas isso é inviável por razões técnicas e econômicas.

A necessidade de transbordos pode ser bastante reduzida com uma adequada configuração espacial da rede de linhas, utilizando linhas circulares que passam diretamente por diversos bairros em complementação às linhas radiais e diametrais que ligam os bairros a região central.

Porém, muitas viagens ainda necessitarão de transferência e, do ponto de vista de justiça social, os sistemas de transporte coletivo deveriam incluir mecanismos que facultassem ao público a acessibilidade a qualquer região da cidade com pagamento de uma única passagem. 
Para KAWAMOTO (1984), a transferência de passageiros de um veículo para outro é um fator que além de interromper e prolongar a viagem, expõe os usuários a certo desconforto e gasto adicional, o que atingiria principalmente os usuários mais carentes que moram na periferia e trabalham na outra extremidade da cidade.

A integração tarifária é feita através de catracas eletrônicas acionadas por cartões que armazenam informações e permitem que o usuário utilize dois ônibus pagando apenas uma passagem, ou ainda pela operação de um terminal urbano fechado que permite a troca de veículos sem nova cobrança.

O fator conectividade pode ser avaliado considerando-se a porcentagem de viagens com necessidade de realizar transbordo, existência de integração física, existência de integração tarifária e tempo de espera nos transbordos.

\section{Comportamento dos operadores}

Enquanto serviço, caracteriza-se o transporte público coletivo urbano, entre outros aspectos, pelo contato direto entre o usuário e o produtor. O funcionário constitui o elo pessoal mais imediato entre o sistema de produção e o cliente. Sozinho a bordo, deve ele cumprir vários preceitos e eventualmente decidir e executar os ajustes da operação.

O contato pessoal do usuário com os prepostos é fundamental, visto que não são todos os serviços que colocam o cliente o tempo todo face a face com o funcionário. No transporte coletivo o contato é permanente e o preposto representa o mais poderoso canal de comunicação ao passageiro, logo a aparência, a conduta e o comportamento profissional dos funcionários podem gerar uma significativa contribuição para a percepção do serviço por parte do usuário.

A parte operacional de uma empresa de ônibus é composta por motoristas e cobradores e vários aspectos caracterizam o comportamento desses junto aos usuários.

No tocante ao motorista, observa-se o comportamento na direção como a realização de paradas obrigatórias (e a razão pela não realização das paradas), o atendimento a idosos 
e outros passageiros com dificuldades de locomoção, atitudes durante a parada (distancia para o meio-fio, modo de parar e de recolocar o veículo em movimento, espera até o ultimo passageiro embarcar ou desembarcar com segurança, arrancada ou partida prudente), modo de direção (direção em curvas, formas de freiar e arrancar, respeito aos sinas e ultrapassagens), a postura e gestos, a forma de prestar informações e conversas efetuadas pelo mesmo.

Quanto ao cobrador observam-se especialmente atos de comunicação verbal e não verbal, a postura frente ao usuário, a maneira do mesmo responder uma informação quando solicitada, prestar assistência ou receber o pagamento pela viagem e efetuar troco corretamente.

Pode-se classificar essa interação com o público em três categorias: agressivo, reservado e comunicativo. Considera-se agressivo o comportamento hostil, através de gestos e palavras quando da passagem do usuário na roleta, da devolução do troco e quando ocorre junção de passageiros nas portas de entrada e saída do veículo. Reservado aplicase ao comportamento ausente de emoções, traduzido em uma figura apática. Comunicativo é utilizado para descrever o comportamento espontâneo em gestos e palavras, contendo diálogo com os passageiros e um semblante agradável.

A avaliação pode ser feita com base nos seguintes itens: condutor dirigindo com habilidade e cuidado e operadores prestativos e educados.

\section{Estado das vias}

Quanto ao estado das vias por onde passam os coletivos, a qualidade da superfície de rolamento tem grande importância a fim de evitar os solavancos provocados por buracos, lombadas e valetas.

A sinalização necessita ser adequada a fim de garantir segurança aos passageiros.

A avaliação se faz considerando os seguintes aspectos: existência ou não de pavimentação, buracos, lombadas e valetas pronunciadas e sinalização adequada. 


\subsection{Padrões de qualidade para o transporte público por ônibus}

É possível definir padrões de qualidade para efeito de planejamento, projeto e avaliação dos sistemas de transporte público urbano, e estes devem se basear na opinião da maioria dos usuários habituais do sistema, em geral pessoas das classes econômicas menos favorecidas.

FERRAZ \& TORRES (2004) relacionam padrões de qualidade para o transporte público urbano os quais são reproduzidos integralmente na tabela 2.2. Vale ressaltar, que esses padrões podem variar de país para país, ou até mesmo de cidade para cidade, em função do porte, por exemplo.

Tabela 2.2 - Padrões de qualidade para o transporte público por ônibus. Fonte: FERRAZ \& TORRES (2004).

\begin{tabular}{|c|c|c|c|c|}
\hline Fatores & Parâmetros de avaliação & Bom & Regular & Ruim \\
\hline \multirow[t]{2}{*}{ Acessibilidade } & $\begin{array}{c}\text { Distância de caminhada no início e fim da } \\
\text { viagem (m) }\end{array}$ & $<300$ & $300-500$ & $>500$ \\
\hline & $\begin{array}{l}\text { Declividade dos percursos não exagerada, } \\
\text { passeios em bom estado e segurança na } \\
\text { travessia das ruas }\end{array}$ & Satisfatório & Deixa a desejar & Insatisfatório \\
\hline Freqüência & Intervalo entre atendimentos ( $\mathrm{min})$ & $<15$ & $15-30$ & $>30$ \\
\hline $\begin{array}{l}\text { Tempo } \\
\text { de viagem }\end{array}$ & $\begin{array}{c}\text { Relação entre o tempo de viagem por ônibus e } \\
\text { por carro }\end{array}$ & $<1,5$ & $1,5-2,5$ & $>2,5$ \\
\hline Lotação & Taxa de passageiros em pé (pass $/ \mathrm{m}^{2}$ ) & $<2,5$ & $2,5-5,0$ & $>5,0$ \\
\hline Confiabilidade & $\begin{array}{c}\text { Viagens não realizadas com adiantamento }> \\
\text { que } 3 \text { min e atraso }>5 \mathrm{~min}\end{array}$ & $<1,0$ & $1,0-3,0$ & $>3,0$ \\
\hline Segurança & Índice de acidentes (acidentes $/ 100.000 \mathrm{~km}$ ) & $<1,0$ & $1,0-2,0$ & $>2,0$ \\
\hline \multirow[t]{4}{*}{$\begin{array}{l}\text { Características } \\
\text { dos ônibus }\end{array}$} & Idade e estado de conservação & $\begin{array}{l}\text { Menos de } 5 \\
\text { anos e em bom } \\
\text { estado }\end{array}$ & $\begin{array}{l}\text { Entre } 5 \text { e } 10 \text { anos } \\
\text { e em bom estado }\end{array}$ & $\begin{array}{l}\text { Outras } \\
\text { situações }\end{array}$ \\
\hline & Número de portas e largura do corredor & $\begin{array}{l}3 \text { portas e } \\
\text { corredor largo }\end{array}$ & $\begin{array}{l}2 \text { portas e } \\
\text { corredor largo }\end{array}$ & $\begin{array}{l}\text { Outras } \\
\text { situações }\end{array}$ \\
\hline & Altura dos degraus & Pequena & Deixa a desejar & Grande \\
\hline & Aparência & Satisfatória & Deixa a desejar & Insatisfatória \\
\hline \multirow{4}{*}{$\begin{array}{l}\text { Características } \\
\text { dos locais } \\
\text { de parada }\end{array}$} & Sinalização & Em todos & Falta em alguns & $\begin{array}{l}\text { Falta em } \\
\text { muitos }\end{array}$ \\
\hline & Cobertura & Na maioria & Falta em muitos & Em poucos \\
\hline & Bancos para sentar & Na maioria & Falta em muitos & Em poucos \\
\hline & Aparência & Satisfatória & Deixa a desejar & Insatisfatória \\
\hline
\end{tabular}




\begin{tabular}{|c|c|c|c|c|}
\hline Fatores & Parâmetros de avaliação & Bom & Regular & Ruim \\
\hline \multirow[t]{3}{*}{$\begin{array}{l}\text { Sistemas } \\
\text { de informações }\end{array}$} & Folhetos com itinerários e horários disponíveis & Sim & $\begin{array}{l}\text { Sim, porém } \\
\text { precário }\end{array}$ & Não existem \\
\hline & Informações adequadas nas paradas & Sim & $\begin{array}{l}\text { Sim, porém } \\
\text { precário }\end{array}$ & Não existem \\
\hline & $\begin{array}{l}\text { Informações e reclamações (pessoalmente ou } \\
\text { por telefone) }\end{array}$ & Sim & $\begin{array}{l}\text { Sim, porém } \\
\text { precário }\end{array}$ & Não existem \\
\hline \multirow[t]{4}{*}{ Conectividade } & Transbordos $(\%)$ & $<15$ & $15-30$ & $>30$ \\
\hline & Integração física & Sim & $\begin{array}{l}\text { Sim, porém } \\
\text { precária }\end{array}$ & Não existe \\
\hline & Integração tarifária & Sim & Não & Não \\
\hline & Tempo de espera nos transbordos (min) & $<15$ & $15-30$ & $>30$ \\
\hline \multirow{2}{*}{$\begin{array}{l}\text { Comportamento } \\
\text { dos operadores }\end{array}$} & Motoristas dirigindo com habilidade e cuidado & Satisfatório & Deixa a desejar & Insatisfatório \\
\hline & Motoristas e cobradores prestativos e educados & Satisfatório & Deixa a desejar & Insatisfatório \\
\hline Estado das vias & $\begin{array}{l}\text { Vias pavimentadas e sem buracos, lombadas e } \\
\text { valetas e com sinalização adequada }\end{array}$ & Satisfatório & Deixa a desejar & Insatisfatório \\
\hline
\end{tabular}

\subsection{Método de avaliação da qualidade adotado pela Prefeitura Municipal de São Carlos}

A metodologia de avaliação da qualidade dos serviços prestados pela concessionária do serviço de transporte coletivo de São Carlos está fundamentada em uma avaliação contínua através da apuração de um conjunto de indicadores relacionados especificamente a atividade operacional e aos recursos empregados na execução do serviço. Desse modo, excluem-se os indicadores que estejam relacionados à ação de planejamento de transporte, exercida pelo poder público, ou que estejam relacionados a questões alheias a possibilidade de atuação da concessionária.

A apuração da qualidade do serviço é realizada mediante a apuração de 10 indicadores, são eles: grau de variação dos intervalos de viagem nos pontos de controle, grau de falhas de veículo em operação, grau de cumprimento de viagens, grau de aprovação da frota em vistorias programadas, grau de aprovação da frota em vistorias de campo, grau de limpeza dos veículos, grau de irregularidades na atuação dos operadores, grau de reclamação dos usuários sobre o serviço, grau de ocorrência de acidentes e grau de ocorrência de irregularidades de trânsito. 
O conceito destes indicadores e a forma de seu cálculo são apresentados na seqüência.

\section{Grau de variação dos intervalos de viagem nos pontos de controle}

O atributo de qualidade do serviço analisado é o tempo de espera e a forma de cálculo é o quadrado do coeficiente de variação do intervalo entre viagens do período analisado, sendo este coeficiente calculado através do quociente entre o desvio padrão da série de intervalos do período analisado, pelo intervalo especificado para este período, tendo como referência o ponto de controle da linha.

O indicador pode ser representado em quatro níveis:

- por linha, dia e período - pico manhã, PM, das 06:30 as 08:29 h, entre-pico manhã, EPM, das 08:30 as 11:59 h, pico almoço, PA, das 12:00 as 13:29 h, entre-pico tarde, EPT, das 13:30 as 16:59 h, pico tarde, PT, das 17:00 as 18:59 h e noite, N, das 19:00 as $22: 59 \mathrm{~h}$;

- por linha, tipo de dia e últimos três meses - média ponderada do indicador dos tipos de dia (útil, sábado e domingo, analisados considerando diferentes pesos de cada período do dia conforme tabela 2.3);

- por concessionária e mês - média ponderada do indicador nas linhas e dias analisados considerando diferentes pesos de cada período e tipo de dia;

- por concessionária e semestre - média do indicador nas linhas e dias analisados.

Tabela 2.3 - Pesos considerados para períodos e tipos de dia.

\begin{tabular}{|c|c|c|c|c|c|}
\hline PM & EPM & PA & EPT & PT & $\mathrm{N}$ \\
\hline 1,0 & 0,8 & 0,9 & 0,8 & 1,0 & 1,0 \\
\hline \multicolumn{2}{|c|}{ Dias úteis } & \multicolumn{2}{|c|}{ Sábados } & \multicolumn{2}{|c|}{ Domingos } \\
\hline \multicolumn{2}{|c|}{1,0} & \multicolumn{2}{|c|}{1,1} & \multicolumn{2}{|c|}{1,2} \\
\hline
\end{tabular}

O indicador é obtido no processo de medição da oferta. 


\section{Grau de falhas de veículo em operação}

O atributo de qualidade do serviço analisado é a confiabilidade, medida pela quebra de veículos no percurso, portanto incidindo sobre o conforto, a regularidade e o tempo de espera, e a forma de cálculo é o quociente da quantidade de quebras de veículo na via pública pela frota empenhada no período medido.

Esse indicador reflete possíveis problemas decorrentes de uma manutenção inadequada dos veículos. Se a manutenção corretiva e preventiva for adequada pressupõe-se que ocorrerão menos falhas mecânicas e menos viagens interrompidas.

O indicador pode ser representado em quatro níveis:

- por linha e dia;

- por linha, tipo de dia e últimos três meses - média do indicador dos tipos de dia (útil, sábado e domingo);

- por concessionária e mês - média do indicador nas linhas e dias analisados;

- por concessionária e semestre - média do indicador nas linhas e dias analisados.

O indicador é obtido no processo de medição da oferta.

\section{Grau de cumprimento de viagens}

$\mathrm{O}$ atributo de qualidade do serviço analisado é a confiabilidade, medida pelo cumprimento de horário das viagens e sendo obtido pelo quociente da quantidade de viagens admitidas pela quantidade de viagens especificadas.

Esse indicador refere-se ao não atingimento das metas propostas pelo órgão gestor, parte-se do pressuposto que, com os insumos definidos pela Prefeitura, a empresa teria condições de cumprir o serviço definido. $\mathrm{O}$ não cumprimento significa não atingir o padrão proposto.

O indicador pode ser representado em quatro níveis: 
- por linha, dia e período - pico manhã, entre-pico manhã, pico almoço, entre-pico tarde, pico tarde e noite;

- por linha, tipo de dia e últimos três meses - média ponderada do indicador dos tipos de dia (útil, sábado e domingo, analisados considerando diferentes pesos de cada período do dia);

- por concessionária e mês - média ponderada do indicador nas linhas e dias analisados considerando diferentes pesos de cada período e tipo de dia;

- por concessionária e semestre - média do indicador nas linhas e dias analisados.

O indicador é encontrado no processo de medição da oferta.

\section{Grau de aprovação da frota em vistorias programadas}

O atributo de qualidade do serviço analisado é a condição do veículo, sendo obtido pelo quociente da somatória da quantidade de veículos aprovados na vistoria pelo total de veículos vistoriados.

Esse indicador refere-se a problemas operacionais, decorrentes de falhas de manutenção, subtendendo-se a eficiência operacional, ou seja, se os veículos estiverem adequados poderão prestar o serviço. Existe um padrão de veículos a serem utilizados e na vistoria procura-se detectar se a empresa está cumprindo esse padrão.

O indicador pode ser representado em dois níveis:

- concessionária e mês;

- concessionária e semestre.

O indicador é encontrado nas vistorias programadas realizadas em todos os veículos. 


\section{Grau de aprovação da frota em vistorias de campo}

O atributo de qualidade do serviço analisado é a condição do veículo, sendo obtido pelo quociente da somatória da quantidade de notificações emitidas por irregularidades da frota e o total de veículos vistoriados em campo, nas várias rotinas de fiscalização.

O indicador pode ser representado em dois níveis:

- concessionária e mês;

- concessionária e semestre.

O indicador é baseado nos relatórios de fiscalização executados em campo.

\section{Grau de limpeza dos veículos}

O atributo de qualidade do serviço analisado é veículo limpo e pode ser obtido do quociente da quantidade de notificações emitidas por falta de limpeza do veículo e o total de veículos vistoriados em campo.

O indicador pode ser representado em dois níveis:

- concessionária e mês;

- concessionária e semestre.

\section{Grau de irregularidades na atuação dos operadores}

O atributo de qualidade do serviço analisado é a condução suave, tratamento respeitoso dos usuários e segurança na direção dos veículos, e pode ser calculado pelo quociente da quantidade de notificações emitidas por problemas com os operadores (motoristas e cobradores) e o total de veículos verificados em rotinas de fiscalização.

O indicador pode ser representado em dois níveis:

- concessionária e mês; 
- concessionária e semestre.

\section{Grau de reclamação dos usuários sobre o serviço}

Este indicador da qualidade do serviço relaciona-se a todos aqueles que possam ser imputados à prestação do serviço, tais como: atuação dos operadores, condições dos veículos quanto a conservação e limpeza, regularidade da operação (intervalos e atrasos) e outros. Pode ser calculado com o quociente da somatória das reclamações de usuários enquadrados nas categorias acima expostas no período analisado pela quantidade de passageiros transportados no mesmo período, e a unidade seria em reclamações por 100.000 passageiros.

O indicador pode ser representado em dois níveis:

- concessionária e mês;

- concessionária e semestre.

\section{Grau de ocorrência de acidentes}

O atributo de qualidade do serviço analisado é a segurança, sendo calculado pelo quociente da quantidade de acidentes e/ou incidentes com ou sem vítima, que tenham sido comprovadamente causados pelo operador ou pelo estado do veículo, pela frota operacional no período, assim considerada a quantidade máxima de veículos em operação em cada um dos dias do período considerado.

O indicador pode ser representado em dois níveis:

- concessionária e mês;

- concessionária e semestre. 


\section{Grau de ocorrência de irregularidades de trânsito}

$\mathrm{O}$ atributo de qualidade do serviço analisado é a segurança, sendo calculado pelo quociente da quantidade de autuações por infrações de trânsito, confirmadas após recursos apresentados, pela frota operacional no período, assim considerada a quantidade máxima de veículos em operação em cada um dos dias do período considerado.

O indicador pode ser representado em dois níveis:

- concessionária e mês;

- concessionária e semestre.

\section{Valores de referência}

Para composição do índice de qualidade geral, os vários indicadores apresentados deverão ser comparados com os valores fixados, que representarão o padrão de referência de qualidade que a Prefeitura Municipal estabelecerá para o serviço. Os valores de cada indicador serão transformados em uma nota de 0 a 100 em função de sua variação em relação ao padrão de referência, expresso através de valores mínimos e máximos.

A tabela 2.4 apresenta os valores para os indicadores e as notas associadas. Caso necessário, poderá ser realizado a revisão da metodologia pela Prefeitura Municipal. 
Tabela 2.4 - Valores para os indicadores e as notas associadas. Fonte: PREFEITURA MUNICIPAL DE SÃO CARLOS (2003).

\begin{tabular}{|c|c|c|c|c|c|c|}
\hline Indicador & Unidade & $\begin{array}{l}\text { Valor } \\
\text { máximo }\end{array}$ & Nota 1 & $\begin{array}{l}\text { Valor } \\
\text { mínimo }\end{array}$ & Nota 2 & $\begin{array}{c}\text { Peso } \\
(\%)\end{array}$ \\
\hline $\begin{array}{l}\text { Grau de variação dos } \\
\text { intervalos de viagem }\end{array}$ & $\%$ & 20 & 0 & 2 & 100 & 5 \\
\hline $\begin{array}{l}\text { Grau de falhas de } \\
\text { veículos }\end{array}$ & Quebras/ veículos & 1,1 & 0 & 0,7 & 100 & 10 \\
\hline $\begin{array}{l}\text { Grau de cumprimento de } \\
\text { viagens }\end{array}$ & $\%$ & 98 & 100 & 80 & 0 & 35 \\
\hline $\begin{array}{l}\text { Grau de aprovação em } \\
\text { vistorias programadas }\end{array}$ & $\begin{array}{l}\text { Notificações/ } \\
\text { veículos }\end{array}$ & 0,07 & 0 & 0,02 & 100 & 3 \\
\hline $\begin{array}{l}\text { Grau de aprovação da } \\
\text { frota no campo }\end{array}$ & $\begin{array}{l}\text { Notificações/ } \\
\text { veículos }\end{array}$ & 0,14 & 0 & 0,04 & 100 & 5 \\
\hline $\begin{array}{l}\text { Grau de limpeza dos } \\
\text { veículos }\end{array}$ & $\begin{array}{l}\text { Notificações/ } \\
\text { veículos }\end{array}$ & 0,25 & 0 & 0,05 & 100 & 5 \\
\hline $\begin{array}{l}\text { Grau de irregularidades } \\
\text { na atuação dos } \\
\text { operadores }\end{array}$ & $\begin{array}{l}\text { Notificações/ } \\
\text { veículos }\end{array}$ & 0,25 & 0 & 0,05 & 100 & 5 \\
\hline $\begin{array}{l}\text { Grau de reclamação dos } \\
\text { usuários sobre o serviço }\end{array}$ & $\begin{array}{c}\text { Reclamações/ } \\
100.000 \\
\text { passageiros }\end{array}$ & 3 & 0 & 2 & 100 & 15 \\
\hline $\begin{array}{l}\text { Grau de ocorrência de } \\
\text { acidentes }\end{array}$ & $\begin{array}{l}\text { Acidentes/ } \\
\text { veículos }\end{array}$ & 0,0033 & 0 & 0,001 & 100 & 12 \\
\hline $\begin{array}{l}\text { Grau de ocorrência de } \\
\text { irregularidades de trânsito }\end{array}$ & $\begin{array}{l}\text { Infrações/ } \\
\text { veículos }\end{array}$ & 0,033 & 0 & 0,01 & 100 & 5 \\
\hline
\end{tabular}

\section{Forma de apuração da nota de cada indicador}

À exceção do indicador que mede o grau de cumprimento de viagens, todos os demais podem ser calculados pela seguinte expressão geral:

$$
N_{j}=100 x \frac{\left(V \max _{j}-V m e d_{j}\right)}{\left(V \max _{j}-V \min _{j}\right)}
$$

Onde:

$N_{j}=$ nota atribuída ao indicador $\mathrm{j}$.

$V \max _{j}=$ valor máximo atribuído ao indicador $\mathrm{j}$.

$V \min _{j}=$ valor mínimo atribuído ao indicador $\mathrm{j}$.

Vmed $_{j}=$ valor apurado do indicador $\mathrm{j}$. 
No caso do indicador que mede o cumprimento de viagens, a equação assume a seguinte expressão:

$$
N_{j}=100 x \frac{\left(\text { Vmed }_{j}-V \min _{j}\right)}{\left(V \max _{j}-V \min _{j}\right)}
$$

\section{Forma de apuração do índice de qualidade geral}

O índice de qualidade geral do serviço de transporte coletivo será calculado através da ponderação da nota de cada indicador por pesos relativos que reflitam a importância relativa de cada atributo considerado.

Assim, pode-se calcular o índice com a seguinte expressão:

$$
Q T C_{K}=\sum_{j=1}^{10} N_{j} x \text { Peso }_{j}
$$

Onde:

$Q T C_{k}=$ índice de qualidade do serviço de transporte no período k, que pode ser mensal ou semestral.

$N_{j}=$ indicador de qualidade $\mathrm{j}$, conforme relacionado anteriormente.

$\mathrm{Peso}_{j}=$ peso do indicador j na composição final do índice de qualidade geral.

\subsection{Pesquisas de opinião em transporte coletivo}

Segundo ANTP (1997), são cinco os principais tipos de pesquisas de opinião realizadas no cenário do transporte coletivo urbano: pesquisas de avaliação de serviço, pesquisas de imagem do serviço, pesquisas de caracterização socioeconômica, pesquisa de expectativas e pesquisas de impacto. 
Pesquisas de avaliação de serviço são aquelas que avaliam a qualidade dos serviços em seus aspectos gerais e pontuais, fornecendo os parâmetros para a formulação de indicadores complementares aos índices de desempenho operacional. São instrumentos mais adequados para subsidiar a ação gerencial voltada para o aperfeiçoamento dos níveis de serviço.

Pesquisas de imagem de serviço são estudos de caráter mais geral que investigam e apresentam as percepções da população a respeito das empresas de transporte e dos serviços que prestam. Levam em conta não somente a opinião sobre o desempenho operacional mas também sobre as próprias empresas operadoras em nível institucional.

Pesquisas de caracterização socioeconômica fornecem dados sobre as características e o perfil socioeconômico dos usuários, tais como renda, classe social, ocupação, instrução, sexo e idade.

Segundo ANTP (1995), pesquisas de expectativas permitem o levantamento das projeções futuras do usuário, sobre o transporte, que podem se referir a expectativas mais amplas, como nível de serviço a ser ofertado, ou a expectativas sobre aspectos mais específicos, como tempo de viagem, lotação e outros. Estas consultas são realizadas em função de inovações e alterações a serem introduzidas no serviço.

Pesquisas de impacto são utilizadas para levantar os efeitos causados pela implantação ou alterações no serviço de transporte, avaliando, através da opinião e da aceitação da população e dos grupos afetados, como as intervenções são percebidas e absorvidas pela comunidade. 


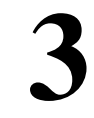

\section{O SISTEMA DE TRANSPORTE COLETIVO DE SÃO CARLOS}

A estrutura urbana de São Carlos é do tipo radial-concêntrica, sendo que a maior parte dos empregos e das oportunidades de consumo de bens e serviços estão localizadas no centro ou ao longo das vias que fazem a ligação da região central com os bairros mais periféricos. Existem dois distritos industriais e diversas universidades (UFSCar, Usp e Unicep) que geram viagens por transporte urbano e estão localizadas fora da região central. Na figura 3.1 encontra-se o mapa do sistema viário de São Carlos.

A rede de transporte público se adequou a esse tipo de estrutura, pois a maior parte das linhas são diametrais, ou seja, unem dois bairros passando pela região central. Existem quatro linhas perimetrais que ligam diversos bairros sem passar pela região central e uma linha circular.

A extensão das linhas existentes ou criação de novas linhas de transporte coletivo para atender às novas regiões que foram ocupadas aconteceu sem uma visão global da rede e do sistema de operação. Como resultado dessa evolução sem um planejamento técnico, tem-se uma rede com várias sobreposições de linhas que afetam a eficiência e a qualidade do serviço ofertado. A figura 3.2 contém a rede de linhas de ônibus de São Carlos. 


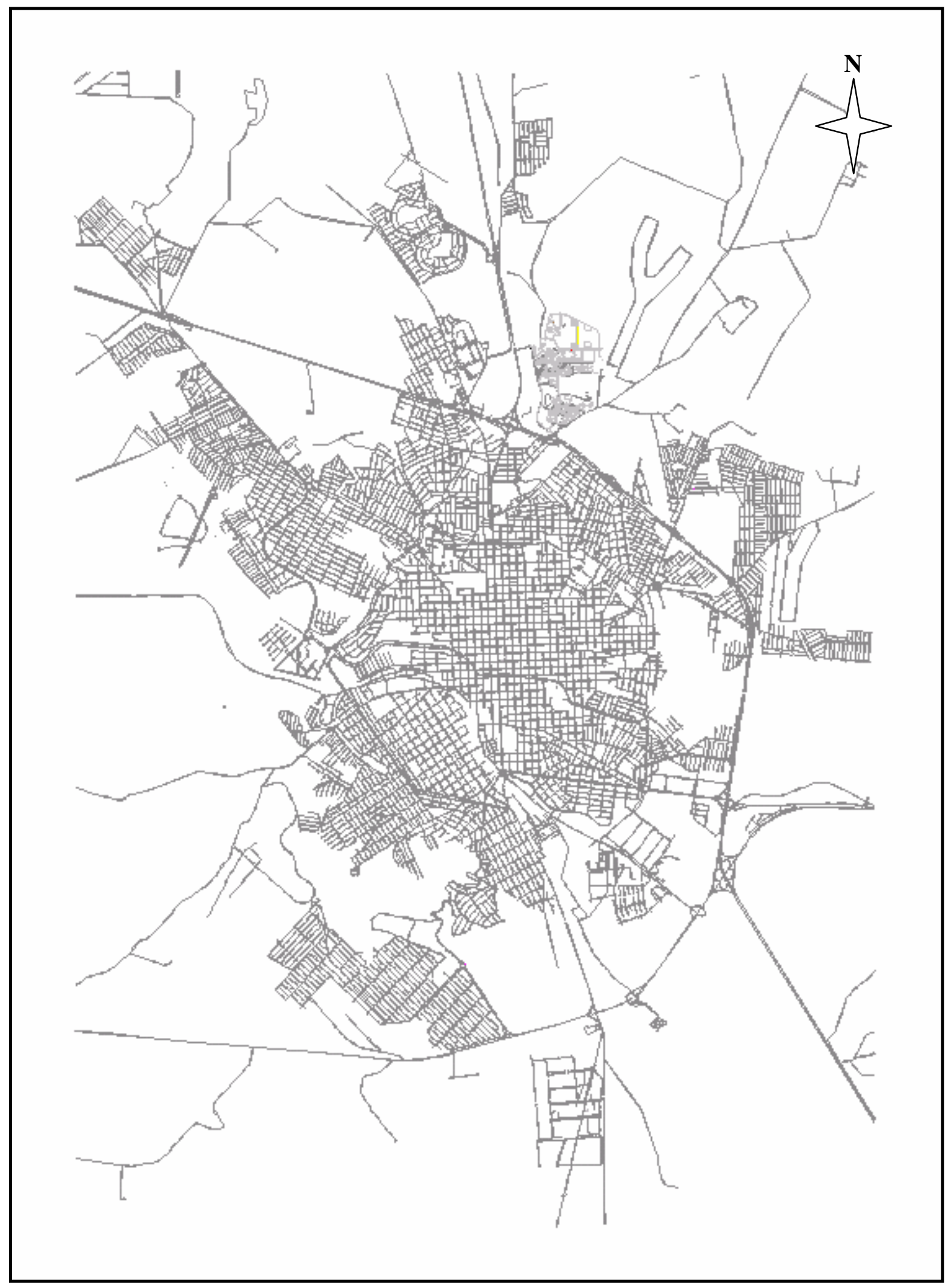

Figura 3.1 - Mapa do sistema viário de São Carlos. 


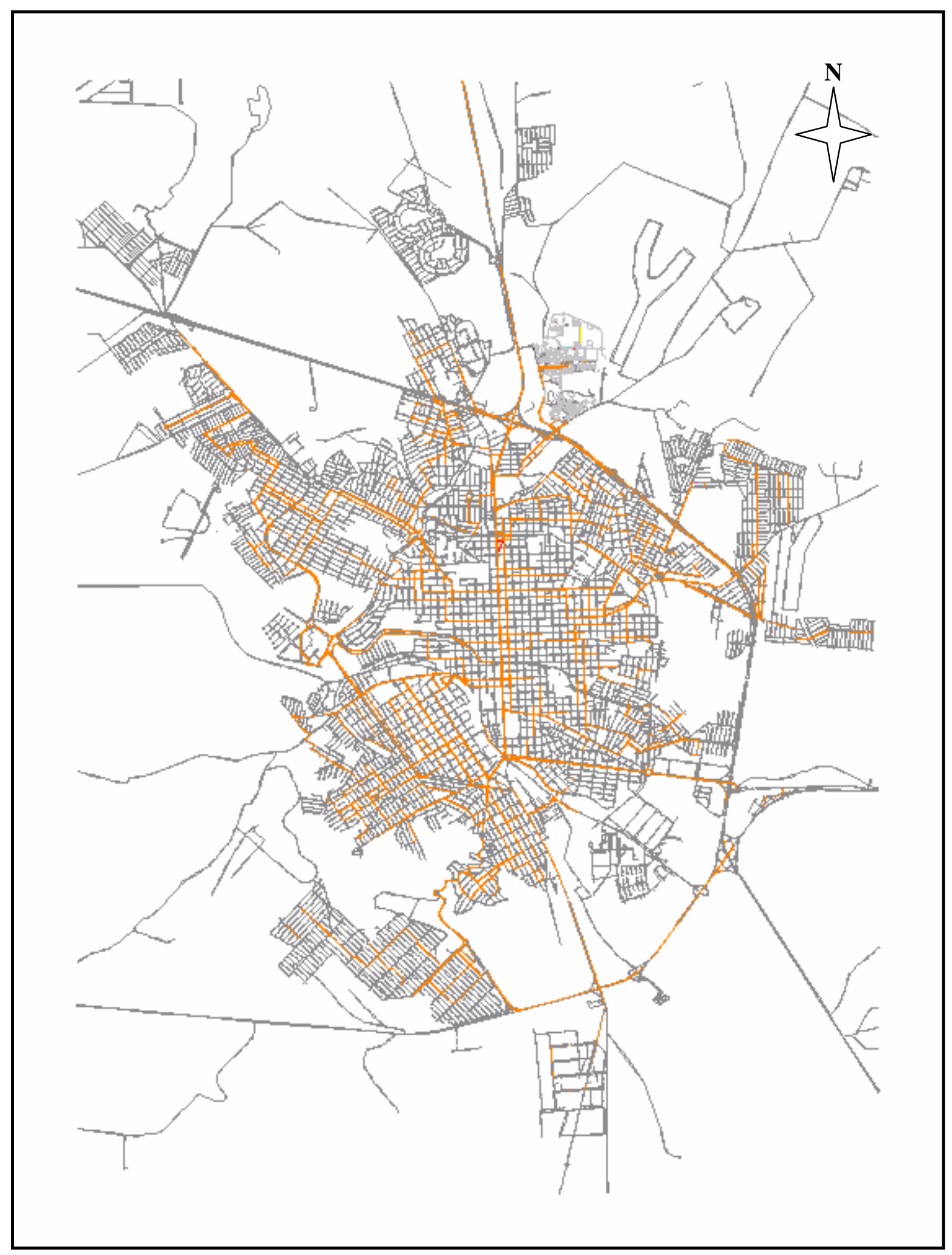

Figura 3.2 - Mapa da rede de linhas de ônibus de São Carlos. 
O sistema possui 53 linhas regulares, relacionadas na tabela 3.1, sendo 45 diametrais, 04 perimetrais, 01 circular e 03 de longa distância, que unem o município-sede a seus distritos. Possuem um ônibus alocado 37 linhas, ou seja, 69,8 \% do total, sendo que nas restantes, $31,2 \%$, operam dois ônibus. Nas linhas regulares são realizadas cerca de 1700 viagens nos dias úteis.

Tabela 3.1 - Relação das linhas regulares

\begin{aligned} & \hline LINHA \multicolumn{1}{c}{ ORIGEM X DESTINO } \\ & \hline 1 PACAEMBU X UFSCar (ÁREA SUL) - VIA BELA VISTA \\ & 2 VILA PRADO X UFSCar (ÁREA NORTE) - VIA PRAÇA ITÁLIA \\ & 4 CASTELO BRANCO X UFSCar (ÁREA SUL) - VIA VILA MONTEIRO \\ & 5 VILA SÃO JOSÉ X REDENÇÃO - VIA PRAÇA ITÁLIA \\ & 6 VILA SÃO JOSÉ X VILA MARCELINO - VIA TAPETE \\ & 7 VILA NERY (M. S. FAGÁ) X SESI - VIA PRAÇA ITÁLIA \\ & 8 VILA NERY (M. S. FAGÁ) X SESI - VIA RUA LARGA \\ & 9 VILA NERY X PACAEMBU - VIA BELA VISTA \\ & 10 VILA PRADO X VILA NERY (PARQUE PRIMAVERA, JD. MUNIQUE II) \\ & 11 CIRCULAR \\ & 12 VILA IZABEL X SANTA PAULA - VIA PRAÇA ITÁLIA \\ & 13 ROMEU TORTORELLI X MARIA STELLA. FAGÁ \\ & 14 SANTA PAULA X REDENÇÃO - VIA BELA VISTA \\ & 15 UFSCar (ÁREA SUL) X BELA VISTA - VIA AEROPORTO \\ & 16 VILA NERY X REDENÇÃO (JD. BEATRIZ) - VIA BOA VISTA \\ & 17 VILA NERY X JD. MARACANÃ - VIA BELA VISTA \\ & 18 VILA SÃO JOSÉ (VILA NERY) X CID. ARACY II - VIA PRAÇA ITÁLIA \\ & 19 UFSCar (ÁREA NORTE) X REDENÇÃO - VIA BOTAFOGO \\ & 20 MARIA STELLA FAGÁ X SHOPPING IGUATEMI \\ & 21 SANTA CASA (USP) X JD. CRUZEIRO DO SUL - VIA BELA VISTA \\ & 22 JD. CRUZEIRO DO SUL X VILA SÃO JOSÉ \\ & 23 BELA VISTA X SANTA FELÍCIA (CONJ. ROMA) \\ & 24 AZULVILLE X SANTA CASA (USP) \\ & \hline\end{aligned}




\begin{tabular}{ll}
\hline LINHA & \multicolumn{1}{c}{ ORIGEM X DESTINO } \\
\hline 30 & MARIA STELLA. FAGÁ X JD. MEDEIROS \\
31 & JD. PAULISTANO X JD. CRUZEIRO DO SUL \\
32 & V. JACOBUCCI X JD. CRUZEIRO DO SUL \\
33 & JD. SÃO RAFAEL X VOLKSWAGEN \\
34 & JOCKEY CLUBE X CENTRO COMUNITÁRIO \\
35 & JD. PAULISTANO X JD. MARACANÃ \\
36 & JACOBUCCI X JD. BEATRIZ \\
37 & SANTA FELÍCIA X JD. GONZAGA - VIA RODOVIÁRIA \\
38 & SANTA FELÍCIA X CID. ARACY - VIA CENTRO COMUNITÁRIO \\
39 & ANTENOR GARCIA X SANTA FELÍCIA - VIA RODOVIÁRIA \\
40 & SANTA FELÍCIA X CIDADE ARACY - VIA BELA VISTA \\
41 & AZULVILLE X SHOPPING IGUATEMI \\
42 & JOCKEY CLUBE X SHOPPING IGUATEMI \\
43 & SÃO CARLOS X ÁGUA VERMELHA \\
44 & SÃO CARLOS X POSTO CASTELO \\
45 & JD. NOVO HORIZONTE X SANTA FELÍCIA \\
46 & SANTA FELÍCIA X D. FRANCISCA - VIA CARDINALLI \\
47 & SANTA FELÍCIA X JD. MEDEIROS - VIA SHOPPING \\
48 & JOCKEY CLUBE X BOTAFOGO \\
49 & SÃO CARLOS X SANTA EUDÓXIA \\
50 & JOCKEY CLUBE X MARIA STELLA FAGÁ - VIA UFSCar \\
51 & MARIA STELLA FAGÁ X SANTA FELÍCIA - VIA SANTA CASA \\
52 & ANTENOR GARCIA X SANTA FELÍCIA - VIA SHOPPING \\
53 & JD. SÃO RAFAEL X SANTA CASA - VIA PRAÇA ITÁLIA E SHOPPING \\
\hline
\end{tabular}

Ao sistema regular são adicionados, nos horários de pico, ônibus extras que realizam aproximadamente 170 viagens por dia, que são denominadas de viagens especiais e estão descritas no apêndice A.

Muitas dessas viagens especiais possuem trajetos específicos para algumas empresas e distritos industriais, com horários pré-determinados, aproximando-se de um sistema fretado. A diferença reside no pagamento normal da tarifa e na possibilidade de utilização da linha por qualquer cidadão. 
A cidade possui uma estação de integração aberta na região norte próxima ao terminal rodoviário, por onde passam dezessete linhas regulares e muitas especiais, possibilitando a integração física das mesmas.

A integração tarifária é obtida com o emprego da bilhetagem eletrônica: aparelhos validadores de cartões inteligentes (dotados de chip) acoplados a catracas eletromecânicas. Com a posse do cartão inteligente o usuário consegue utilizar dois ônibus de linhas diferentes pagando apenas uma passagem no intervalo de noventa minutos.

O pagamento da passagem também pode ser feito com dinheiro ou passe-cidadão, modalidade em papel distribuída pela Prefeitura Municipal com fins sociais, porém, nesses casos, não é possível fazer a integração tarifária.

O intervalo entre atendimentos nas linhas regulares é de 60 minutos e o sistema possui 1050 pontos de embarque e desembarque, sendo que 143 são cobertos.

A operadora do sistema é a Athenas Paulista, empresa vencedora do último processo licitatório. O contrato de prestação de serviço de transporte de passageiros iniciou em 17/05/2004 com vigência de 10 anos e a frota da concessionária é de 86 ônibus, 20 microônibus e três veículos adaptados às pessoas com necessidades especiais. A frota percorre cerca de 740.000 quilômetros por mês. Em média são registrados 50.000 passageiros por dia a uma tarifa de R\$1,70, reajustada em 11 de junho de 2005. 


\section{DIAGNÓSTICO SOBRE A \\ QUALIDADE DO SERVIÇO}

\subsection{Avaliação baseada em entrevistas realizadas com usuários}

\section{Objetivos da pesquisa}

Esta pesquisa tem como objetivos:

- Avaliar o grau de satisfação dos usuários de ônibus de São Carlos com os fatores de qualidade explicitados no capítulo 2.

- Apurar qual a importância que o usuário atribui a cada um desses fatores.

\section{Metodologia utilizada}

Trata-se de uma pesquisa quantitativa com abordagem pessoal e aplicação individual de questionário estruturado, conforme modelo apresentado no apêndice B. As respostas dos entrevistados têm como objetivo avaliar apenas as características da linha de ônibus que ele está utilizando. 
A pesquisa foi realizada em São Carlos nos dias 10, 11, 12, 13, 14, 17 e 18 de Outubro de 2005, das 08:00 às 18:00 horas, no interior dos ônibus que estão alocados nas 53 linhas existentes na cidade. A equipe era formada por cinco pesquisadores e um supervisor.

O número de entrevistados (tamanho da amostra) em cada linha é mostrado na tabela 4.1.

Tabela 4.1 - Porcentagem de usuários referente a cada linha e quantidade de entrevistas.

\begin{tabular}{|c|c|c|c|c|c|}
\hline Linha & $\%$ & $\begin{array}{c}\text { Quantidade de } \\
\text { entrevistas }\end{array}$ & Linha & $\%$ & $\begin{array}{c}\text { Quantidade de } \\
\text { entrevistas }\end{array}$ \\
\hline 1 & 1,6 & 17 & 21 & 1,6 & 17 \\
\hline 2 & 2,9 & 30 & 22 & 1,3 & 14 \\
\hline 3 & 1,6 & 17 & 23 & 2,3 & 24 \\
\hline 4 & 1,3 & 14 & 24 & 1,0 & 10 \\
\hline 5 & 1,6 & 17 & 25 & 2,3 & 24 \\
\hline 6 & 1,0 & 10 & 26 & 1,3 & 14 \\
\hline 7 & 1,6 & 17 & 27 & 2,9 & 30 \\
\hline 8 & 1,9 & 20 & 28 & 0,6 & 7 \\
\hline 9 & 1,0 & 10 & 29 & 1,3 & 14 \\
\hline 10 & 1,0 & 10 & 30 & 3,5 & 37 \\
\hline 11 & 0,6 & 7 & 31 & 1,6 & 17 \\
\hline 12 & 1,0 & 10 & 32 & 1,6 & 17 \\
\hline 13 & 3,2 & 34 & 33 & 2,6 & 27 \\
\hline 14 & 1,3 & 14 & 34 & 1,9 & 20 \\
\hline 15 & 2,3 & 24 & 35 & 1,6 & 17 \\
\hline 16 & 1,0 & 10 & 36 & 1,6 & 17 \\
\hline 17 & 1,0 & 10 & 37 & 2,9 & 30 \\
\hline 18 & 3,5 & 37 & 38 & 3,9 & 41 \\
\hline 19 & 1,9 & 20 & 39 & 4,2 & 44 \\
\hline 20 & 2,3 & 24 & 40 & 3,9 & 41 \\
\hline
\end{tabular}




\begin{tabular}{cccccc}
\hline Linha & $\%$ & $\begin{array}{c}\text { Quantidade de } \\
\text { entrevistas }\end{array}$ & Linha & $\%$ & $\begin{array}{c}\text { Quantidade de } \\
\text { entrevistas }\end{array}$ \\
\hline 41 & 1,0 & 10 & 48 & 2,6 & 27 \\
42 & 1,0 & 10 & 49 & 1,3 & 14 \\
43 & 1,0 & 10 & 50 & 1,6 & 17 \\
44 & 0,6 & 7 & 51 & 1,9 & 20 \\
45 & 1,6 & 17 & 52 & 2,3 & 24 \\
46 & 1,3 & 14 & 53 & 1,3 & 14 \\
47 & 0,3 & 3 & $54 *$ & 4,8 & 51 \\
\hline
\end{tabular}

* viagens especiais

$\mathrm{Na}$ pesquisa foram entrevistadas apenas pessoas com idade superior a 15 anos, englobando todas as categorias de usuários: que pagam tarifa integral, com direito a gratuidade total (idosos e deficientes) ou parcial, tais como estudantes. A amostra é composta de 1050 entrevistas, distribuídas dentre os vários segmentos de usuários do sistema, conforme indicado na tabela 4.2.

Tabela 4.2 - Quantidade de usuários pesquisados por categoria.

\begin{tabular}{lcc}
\multicolumn{1}{c}{ Categoria } & Quantidade & $\%$ \\
\hline Comum & 434 & $41,3 \%$ \\
Trabalhador & 335 & $31,9 \%$ \\
Estudante & 200 & $19,1 \%$ \\
Idoso/deficiente & 81 & $7,7 \%$ \\
\hline Total & 1050 & $100 \%$ \\
\hline
\end{tabular}

\section{Resultados obtidos}

As notas, de 1 a 5 (1 - nenhuma importância, 2 - baixa importância, 3 - média importância, 4 - importante e 5 - extremamente importante) emitidas por todos os entrevistados, relacionadas à importância dos fatores de qualidade, foram tabuladas e as médias simples são apresentadas na Tabela 4.3. 
Tabela 4.3 - Importância dos fatores de qualidade

\begin{tabular}{lc}
\multicolumn{1}{c}{ Fatores de Qualidade } & Importância \\
\hline Acessibilidade & 4,3 \\
Freqüência & 4,2 \\
Tempo de Viagem & 3,5 \\
Lotação & 4,1 \\
Confiabilidade & 4,1 \\
Segurança & 4,3 \\
Veículos & 4,2 \\
Locais de Parada & 4,2 \\
Sistema de Informação & 3,6 \\
Conectividade & 4,1 \\
Operadores & 4,1 \\
Vias & 4,2 \\
Soma & 48,9 \\
\hline
\end{tabular}

Acessibilidade e segurança são os fatores mais importantes na opinião dos usuários. A seguir vêm freqüência, características dos veículos, características dos locais de parada e o estado das vias.

Um terceiro grupo dos atributos mais importantes em relação ao total de citações pode ser formado pelos quesitos lotação, confiabilidade, conectividade e comportamento dos operadores.

Sistema de informação e tempo de viagem são os itens de menor importância na opinião do usuário.

Mediante a apresentação dos fatores de qualidade foi solicitado aos entrevistados que atribuíssem uma nota de 1 a 5, que refletisse a opinião sobre o desempenho de cada um deles, na seguinte escala: 5 - ótimo, 4 - bom, 3 - regular, 2 - ruim e 1 - péssimo.

Os valores médios das notas obtidas estão relacionados na tabela 4.4 e na figura 4.1. Observa-se que a maior parte dos fatores apresenta uma avaliação positiva, pois a nota 
média está acima de três, ou seja, entre regular e bom. Lotação, características dos locais de parada, sistema de informação e estado das vias apresentam as menores notas de avaliação (entre ruim e regular).

\begin{tabular}{lc} 
Tabela 4.4 - Desempenho dos fatores de qualidade \\
\hline Fatores de Qualidade & Desempenho \\
\hline Acessibilidade & 3,7 \\
Freqüência & 3,3 \\
Tempo de Viagem & 3,4 \\
Lotação & 2,7 \\
Confiabilidade & 3,2 \\
Segurança & 3,6 \\
Veículos & 3,5 \\
Locais de Parada & 2,6 \\
Sistema de Informação & 2,5 \\
Conectividade & 3,5 \\
Operadores & 3,9 \\
Vias & 2,2
\end{tabular}

Também na figura 4.1 estão indicados os valores da média simples das notas do desempenho dos fatores e da média ponderada com base nos valores individuais da importância atribuída. 


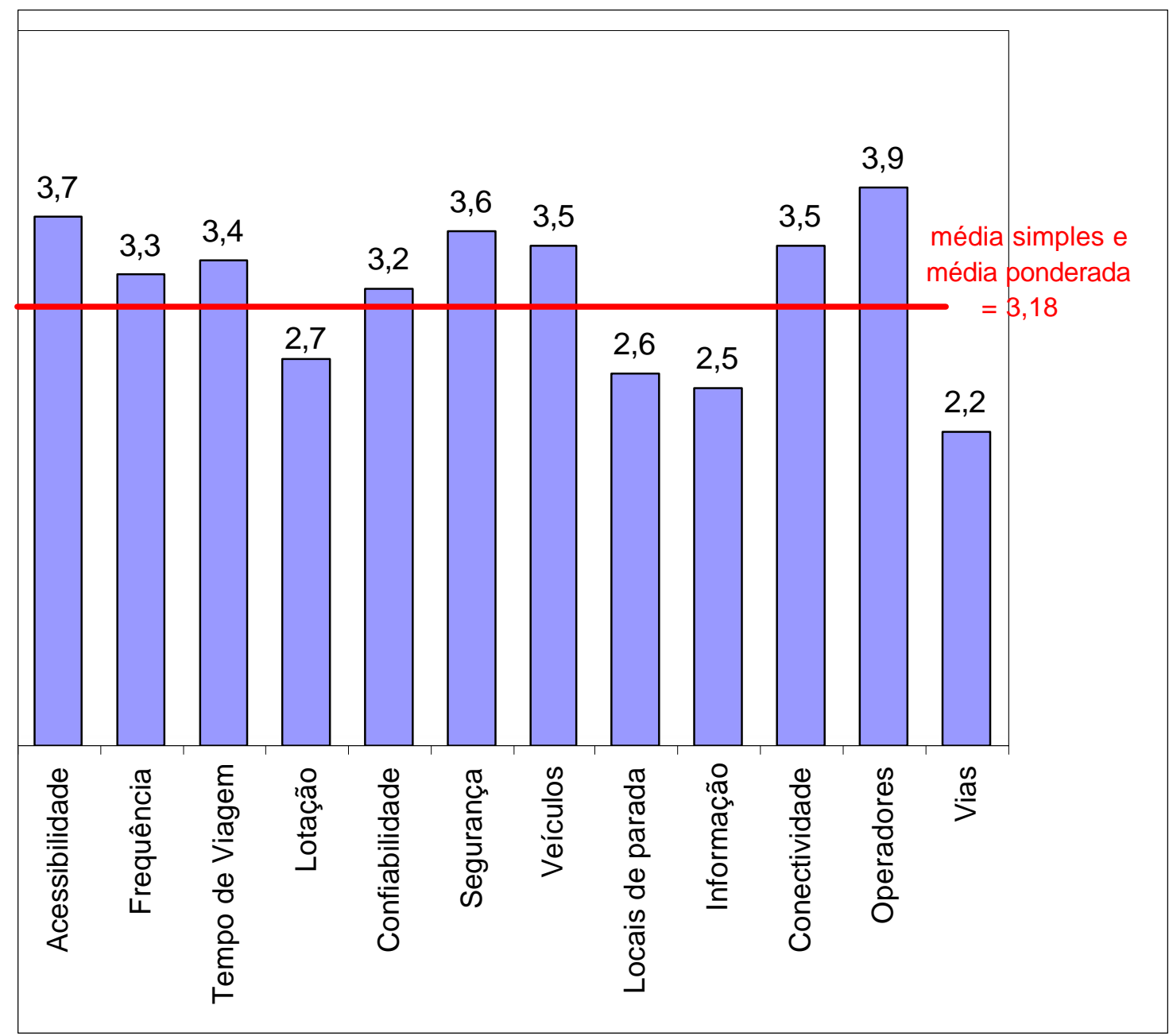

Figura 4.1 - Avaliação do desempenho dos fatores de qualidade

No apêndice C estão detalhadas as avaliações de cada fator de qualidade do transporte coletivo de São Carlos, de acordo com a opinião dos usuários entrevistados.

A associação entre os valores atribuídos á importância dos fatores de qualidade e os valores atribuídos ao desempenho obtidos na pesquisa com os usuários, é mostrado na figura 4.2.

O eixo das abcissas corresponde à importância e o das ordenadas ao desempenho. As linhas divisórias são colocadas arbitrariamente com o objetivo de separar o gráfico em quadrantes para que os fatores possam ser avaliados de acordo com a região em que se situam. 


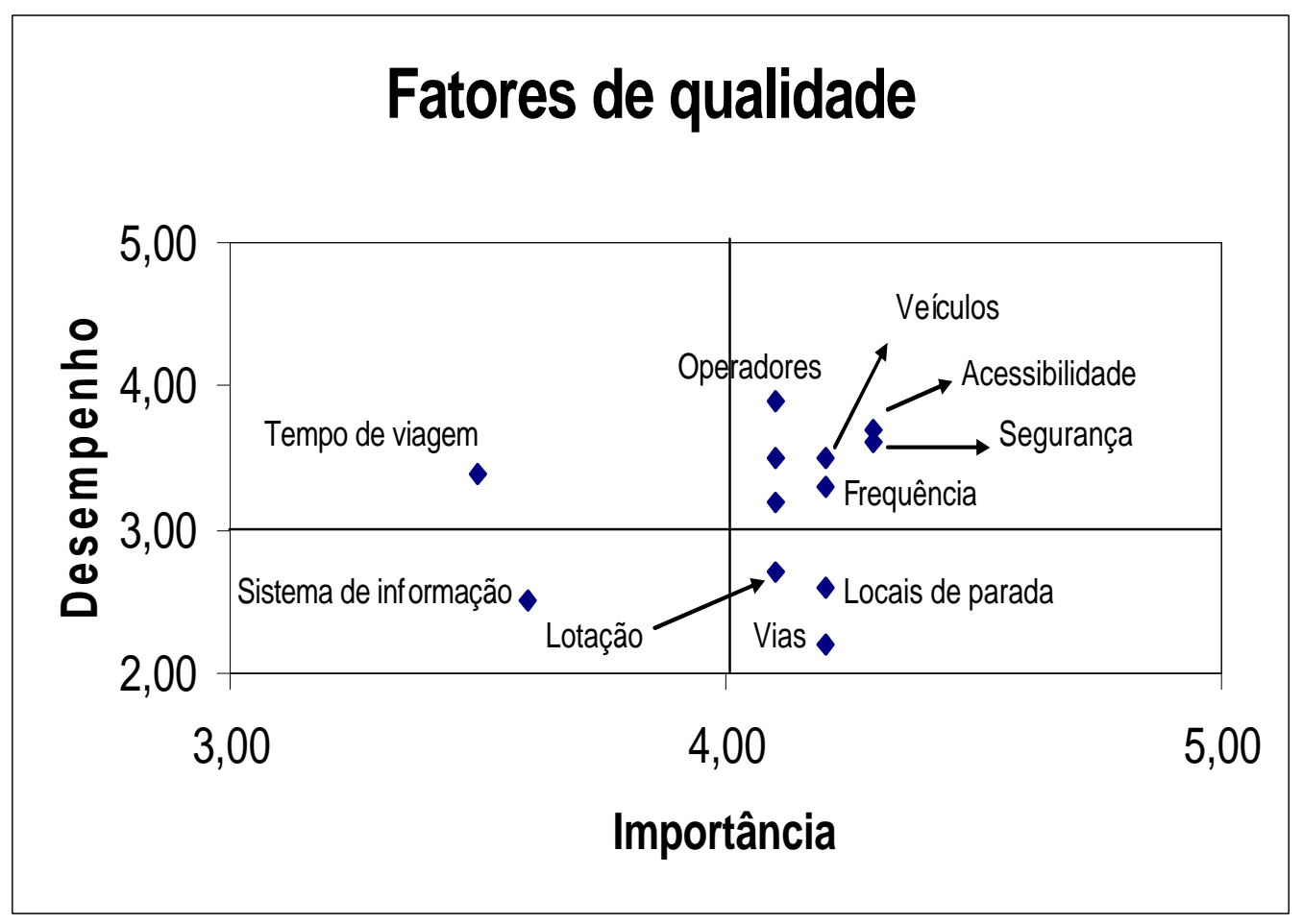

Figura 4.2 - Desempenho x Importância dos fatores de qualidade

No lado esquerdo inferior do gráfico está a região de menor importância e desempenho: onde se encontra o fator sistema de informação. Qualquer melhoria nesse fator terá pouco impacto na percepção de melhoria de qualidade por parte do usuário, uma vez que ele não tem grande importância.

No lado esquerdo superior, região de menor importância e desempenho satisfatório, encontra-se o fator tempo de viagem.

$\mathrm{Na}$ parte direita superior do gráfico encontra-se a região de excelência, ou seja, maior importância e desempenho satisfatório. Nessa condição estão os fatores: acessibilidade, freqüência, confiabilidade, segurança, características dos veículos, conectividade e comportamento dos operadores.

$\mathrm{Na}$ parte inferior direita do gráfico, região de maior importância e desempenho insatisfatório, encontram-se os fatores lotação, locais de parada e estados das vias. 


\subsection{Avaliação realizada pela Prefeitura Municipal}

O resultado da avaliação realizada pela Prefeitura, conforme metodologia anteriormente descrita encontra-se na Tabela 4.5, e refere-se aos primeiros seis meses de operação, compreendido entre o início do contrato no dia 17/05/2004 e 16/11/2004.

Tabela 4.5 - Resultado da avaliação dos indicadores.

Fonte: PREFEITURA MUNICIPAL DE SÃO CARLOS (2004).

\begin{tabular}{|c|c|c|c|c|c|c|}
\hline Indicador & Unidade & $\begin{array}{l}\text { Valor } \\
\text { máximo }\end{array}$ & $\begin{array}{c}\text { Valor } \\
\text { mínimo }\end{array}$ & Semestre & Nota & $\begin{array}{c}\text { Peso } \\
(\%)\end{array}$ \\
\hline $\begin{array}{l}\text { Grau de variação dos } \\
\text { intervalos de viagem }\end{array}$ & $\%$ & 20 & 2 & 0 & 100 & 5 \\
\hline $\begin{array}{l}\text { Grau de falhas de } \\
\text { veículos }\end{array}$ & Quebras/veículos & 1,1 & 0,7 & 0 & 100 & 10 \\
\hline $\begin{array}{l}\text { Grau de cumprimento de } \\
\text { viagens }\end{array}$ & $\%$ & 98 & 80 & $94,33 \%$ & 79,63 & 35 \\
\hline $\begin{array}{l}\text { Grau de aprovação em } \\
\text { vistorias programadas }\end{array}$ & $\begin{array}{l}\text { Notificações/ } \\
\text { veículos }\end{array}$ & 0,07 & 0,02 & 0,2719 & 0 & 3 \\
\hline $\begin{array}{l}\text { Grau de aprovação da } \\
\text { frota no campo }\end{array}$ & $\begin{array}{l}\text { Notificações/ } \\
\text { veículos }\end{array}$ & 0,14 & 0,04 & 0 & 100 & 5 \\
\hline $\begin{array}{l}\text { Grau de limpeza dos } \\
\text { veículos }\end{array}$ & $\begin{array}{l}\text { Notificações/ } \\
\text { veículos }\end{array}$ & 0,25 & 0,05 & 0 & 100 & 5 \\
\hline $\begin{array}{l}\text { Grau de irregularidades } \\
\text { na atuação dos } \\
\text { operadores }\end{array}$ & $\begin{array}{l}\text { Notificações/ } \\
\text { veículos }\end{array}$ & 0,25 & 0,05 & 0 & 100 & 5 \\
\hline $\begin{array}{l}\text { Grau de reclamação dos } \\
\text { usuários sobre o serviço }\end{array}$ & $\begin{array}{l}\text { Reclamações/ } \\
100.000 \text { pass }\end{array}$ & 3 & 2 & 1,86 & 100 & 15 \\
\hline $\begin{array}{l}\text { Grau de ocorrência de } \\
\text { acidentes }\end{array}$ & $\begin{array}{l}\text { Acidentes/ } \\
\text { veículos }\end{array}$ & 0,0033 & 0,001 & 0,0005 & 100 & 12 \\
\hline $\begin{array}{l}\text { Grau de ocorrência de } \\
\text { irregularidades de trânsito }\end{array}$ & $\begin{array}{l}\text { Infrações/ } \\
\text { veículos }\end{array}$ & 0,033 & 0,01 & 0,0003 & 100 & 5 \\
\hline
\end{tabular}

Analisando a tabela 4.5, nota-se que na coluna Semestre para vários indicadores variação dos intervalos de viagens, falhas de veículos, aprovação da frota no campo, limpeza dos veículos e irregularidades na atuação dos operadores - aparece o número 0 e a Nota correspondente a 100. Nesses casos a Secretaria de Transportes não conseguiu implantar a metodologia para medição do valor real do indicador e a empresa recebeu a nota máxima.

Neste caso, utilizando a metodologia descrita no capítulo 2 , obtém-se a nota final da avaliação da concessão dos serviços do $1^{\circ}$. semestre: $Q T C_{I}=89,87$ pontos. 
Os dados da tabela 4.6 referem-se ao segundo semestre de operação, compreendido entre 17/11/04 e 16/05/2005. Neste caso observa-se um aumento de cinco para oito no número de indicadores medidos pela gerenciadora do sistema.

Tabela 4.6 - Resultado da avaliação dos indicadores do $2^{\circ}$ semestre. Fonte: PREFEITURA MUNICIPAL DE SÃO CARLOS (2005).

\begin{tabular}{|c|c|c|c|c|c|c|}
\hline Indicador & Unidade & $\begin{array}{l}\text { Valor } \\
\text { máximo }\end{array}$ & $\begin{array}{l}\text { Valor } \\
\text { mínimo }\end{array}$ & Semestre & Nota & $\begin{array}{r}\text { Peso } \\
(\%)\end{array}$ \\
\hline $\begin{array}{l}\text { Grau de variação dos } \\
\text { intervalos de viagem }\end{array}$ & $\%$ & 20 & 2 & 0 & 100 & 5 \\
\hline $\begin{array}{l}\text { Grau de falhas de } \\
\text { veículos }\end{array}$ & Quebras/veículos & 1,1 & 0,7 & 0 & 100 & 10 \\
\hline $\begin{array}{l}\text { Grau de cumprimento de } \\
\text { viagens }\end{array}$ & $\%$ & 98 & 80 & $97,67 \%$ & 98,15 & 35 \\
\hline $\begin{array}{l}\text { Grau de aprovação em } \\
\text { vistorias programadas }\end{array}$ & $\begin{array}{l}\text { Notificações/ } \\
\text { veículos }\end{array}$ & 0,07 & 0,02 & 0,0439 & 52,20 & 3 \\
\hline $\begin{array}{l}\text { Grau de aprovação da } \\
\text { frota no campo }\end{array}$ & $\begin{array}{l}\text { Notificações/ } \\
\text { veículos }\end{array}$ & 0,14 & 0,04 & 0,0327 & 100 & 5 \\
\hline $\begin{array}{l}\text { Grau de limpeza dos } \\
\text { veículos }\end{array}$ & $\begin{array}{l}\text { Notificações/ } \\
\text { veículos }\end{array}$ & 0,25 & 0,05 & 0,0060 & 100 & 5 \\
\hline $\begin{array}{l}\text { Grau de irregularidades } \\
\text { na atuação dos } \\
\text { operadores }\end{array}$ & $\begin{array}{l}\text { Notificações/ } \\
\text { veículos }\end{array}$ & 0,25 & 0,05 & 0,0367 & 100 & 5 \\
\hline $\begin{array}{l}\text { Grau de reclamação dos } \\
\text { usuários sobre o serviço }\end{array}$ & $\begin{array}{c}\text { Reclamações/ } \\
100.000 \text { pass }\end{array}$ & 3 & 2 & 4,4595 & 0 & 15 \\
\hline $\begin{array}{l}\text { Grau de ocorrência de } \\
\text { acidentes }\end{array}$ & $\begin{array}{l}\text { Acidentes/ } \\
\text { veículos }\end{array}$ & 0,0033 & 0,001 & 0,0013 & 89,13 & 12 \\
\hline $\begin{array}{l}\text { Grau de ocorrência de } \\
\text { irregularidades de trânsito }\end{array}$ & $\begin{array}{l}\text { Infrações/ } \\
\text { veículos }\end{array}$ & 0,033 & 0,01 & 0,0010 & 100 & 5 \\
\hline
\end{tabular}

Neste caso, utilizando novamente a metodologia descrita no capítulo 2, obtém-se a nota final da avaliação da concessão dos serviços do $2^{\circ}$. semestre, $Q T C_{2}=81,61$ pontos.

$\mathrm{Na}$ análise conjunta dos dois semestres, nota-se que apesar de não ter conseguido implantar a metodologia para a medição de todos os indicadores a que se propôs, a gerenciadora emitiu uma nota final bastante favorável à empresa prestadora do serviço.

Vale ressaltar que existem indicadores relacionados com a área de manutenção e alguns indicadores operacionais, entretanto não existe um acompanhamento direto da opinião dos clientes sobre a qualidade do serviço por parte da Secretaria de Transportes. 


\subsection{Avaliação subjetiva realizada por técnicos}

Nesta avaliação foram ouvidos três especialistas, adotando-se a sistemática preconizada por FERRAZ \& TORRES (2004). Os resultados da avaliação estão resumidos na Tabela 4.7, sendo que das três opiniões foi adotada aquela que tivesse duas ou mais posições idênticas.

Tabela 4.7 - Avaliação técnica da qualidade

\begin{tabular}{|c|c|c|}
\hline Fatores & Parâmetros & Avaliação \\
\hline \multirow[t]{2}{*}{ Acessibilidade } & Distância de caminhada no início e fim da viagem (m) & Bom \\
\hline & Declividade dos percursos não exagerada, passeios em bom estado & Regular \\
\hline Freqüência & Intervalo entre atendimentos (min) & Ruim \\
\hline Tempo de viagem & Relação entre o tempo de viagem por ônibus e por carro & Regular \\
\hline Lotação & Taxa de passageiros em pé (pass $/ \mathrm{m}^{2}$ ) & Regular \\
\hline Confiabilidade & Viagens não realizadas com adiantamento $>$ que 3 e atraso $>5$ min & Regular \\
\hline Segurança & Índice de acidentes (acidentes/100.000 km) & Regular \\
\hline \multirow{4}{*}{$\begin{array}{l}\text { Características } \\
\text { dos ônibus }\end{array}$} & Idade e estado de conservação & Regular \\
\hline & Número de portas e largura do corredor & Regular \\
\hline & Altura dos degraus & Regular \\
\hline & Aparência & Bom \\
\hline \multirow{4}{*}{$\begin{array}{l}\text { Características } \\
\text { dos locais de parada }\end{array}$} & Sinalização & Regular \\
\hline & Cobertura & Ruim \\
\hline & Bancos para sentar & Ruim \\
\hline & Aparência & Ruim \\
\hline \multirow{3}{*}{$\begin{array}{l}\text { Sistemas } \\
\text { de informações }\end{array}$} & Folhetos com itinerários e horários disponíveis & Bom \\
\hline & Informações adequadas nas paradas & Regular \\
\hline & Informações e reclamações (pessoalmente ou por telefone) & Bom \\
\hline \multirow[t]{4}{*}{ Conectividade } & Transbordos $(\%)$ & Bom \\
\hline & Integração física & Bom \\
\hline & Integração tarifária & Bom \\
\hline & Tempo de espera nos transbordos (min) & Regular \\
\hline \multirow{2}{*}{$\begin{array}{l}\text { Comportamento } \\
\text { dos operadores }\end{array}$} & Motoristas dirigindo com habilidade e cuidado & Bom \\
\hline & Motoristas e cobradores prestativos e educados & Bom \\
\hline Estado das vias & Vias pavimentadas e sem buracos, valetas e com sinalização adequada & Regular \\
\hline
\end{tabular}

Nota-se que das vinte e cinco avaliações necessárias para compor os doze fatores de qualidade, nove (36\%) são boas, doze (48\%) são regulares e quatro (16\%) são ruins. 


\subsection{Análises desagregadas da pesquisa de opinião}

Como os questionários aplicados na pesquisa de opinião são identificados por linha e tipo de usuário, é possível proceder à mesma análise realizada globalmente de forma desagregada: por linha e por tipo de usuário.

Como exemplo, são apresentadas a seguir análise dos resultados relativos à linha 2 (Vila Prado - UFSCar) e daqueles relativos ao segmento de usuários denominado "trabalhador".

\section{Análise da linha 2 (Vila Prado - UFSCar)}

Na Tabela 4.8 são apresentados os resultados obtidos na pesquisa de avaliação de importância e do desempenho dos fatores de qualidade relativos a linha 2.

\begin{tabular}{lcc} 
Tabela 4.8 - Resumo dos resultados para a linha 2 Vila Prado - UFSC \\
Fatores de Qualidade & Desempenho & Importância \\
\hline Acessibilidade & 3,8 & 4,1 \\
Freqüiência & 2,9 & 4,3 \\
Tempo de Viagem & 3,4 & 3,7 \\
Lotação & 2,5 & 4,4 \\
Confiabilidade & 3,2 & 4,0 \\
Segurança & 4,3 & 4,4 \\
Veículos & 3,4 & 4,1 \\
Locais de Parada & 2,8 & 4,0 \\
Sistema de Informação & 2,5 & 3,8 \\
Conectividade & 3,6 & 4,0 \\
Operadores & 4,1 & 4,1 \\
Vias & 2,2 & 4,2 \\
\hline
\end{tabular}

Lotação, segurança e freqüência são os atributos mais importantes na opinião dos usuários da linha 2. A seguir tem-se estado das vias, acessibilidade, características dos veículos e comportamento dos operadores. 
Um terceiro grupo dos atributos mais importantes em relação ao total de citações pode ser formado pelos quesitos confiabilidade, características dos locais de parada e conectividade.

Tempo de viagem e sistema de informação são os itens de menor importância na opinião dos usuários da linha 2.

Na figura 4.3 é mostrado o gráfico do desempenho versus importância dos fatores de qualidade.

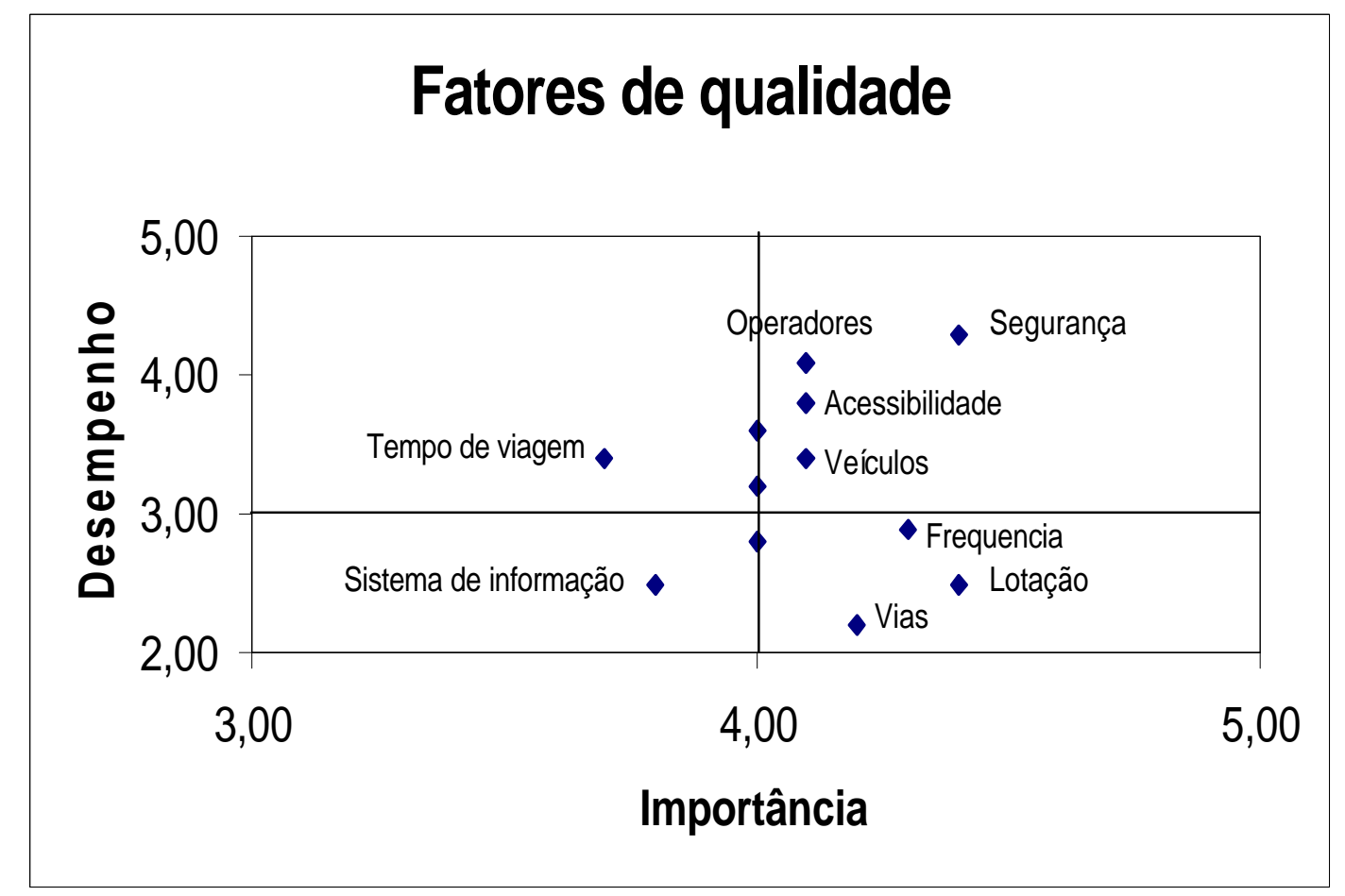

Figura 4.3 - Desempenho x Importância dos fatores de qualidade da linha 2 Vila Prado - UFSCar

Esse estudo pode ser aplicado para cada linha da cidade com objetivo de mapear as opiniões dos usuários e identificar os problemas específicos, facilitando a adoção de ações corretivas localizadas no espaço. 


\section{Análise do segmento "trabalhador"}

Na tabela 4.9 são apresentados os resultados obtidos na pesquisa de avaliação da importância e do desempenho dos fatores de qualidade para o segmento "trabalhador".

\begin{tabular}{lcc}
\multicolumn{3}{c}{ Tabela 4.9 - Resumo dos resultados para o segmento "trabalhador" } \\
\hline Fatores de Qualidade & Desempenho & Importância \\
\hline Acessibilidade & 3,5 & 4,3 \\
Freqüiência & 3,1 & 4,1 \\
Tempo de Viagem & 3,5 & 3,9 \\
Lotação & 2,6 & 3,9 \\
Confiabilidade & 3,3 & 4,3 \\
Segurança & 3,5 & 4,2 \\
Veículos & 3,4 & 4,1 \\
Locais de Parada & 2,8 & 4,2 \\
Sistema de Informação & 2,6 & 3,8 \\
Conectividade & 3,4 & 4,1 \\
Operadores & 3,9 & 4,0 \\
Vias & 2,3 & 4,2 \\
\hline
\end{tabular}

Acessibilidade e confiabilidade são os atributos mais importantes na opinião dos trabalhadores. A seguir tem-se segurança, características dos locais de parada e o estado das vias.

Um terceiro grupo dos atributos mais importantes em relação ao total de citações pode ser formado pelos quesitos frequiência, características dos veículos, conectividade e comportamento dos operadores.

Sistema de informação, tempo de viagem e lotação são os itens de menor importância na opinião dos trabalhadores.

Na figura 4.4 é mostrado o gráfico do desempenho versus importância dos fatores de qualidade para o segmento "trabalhador". 


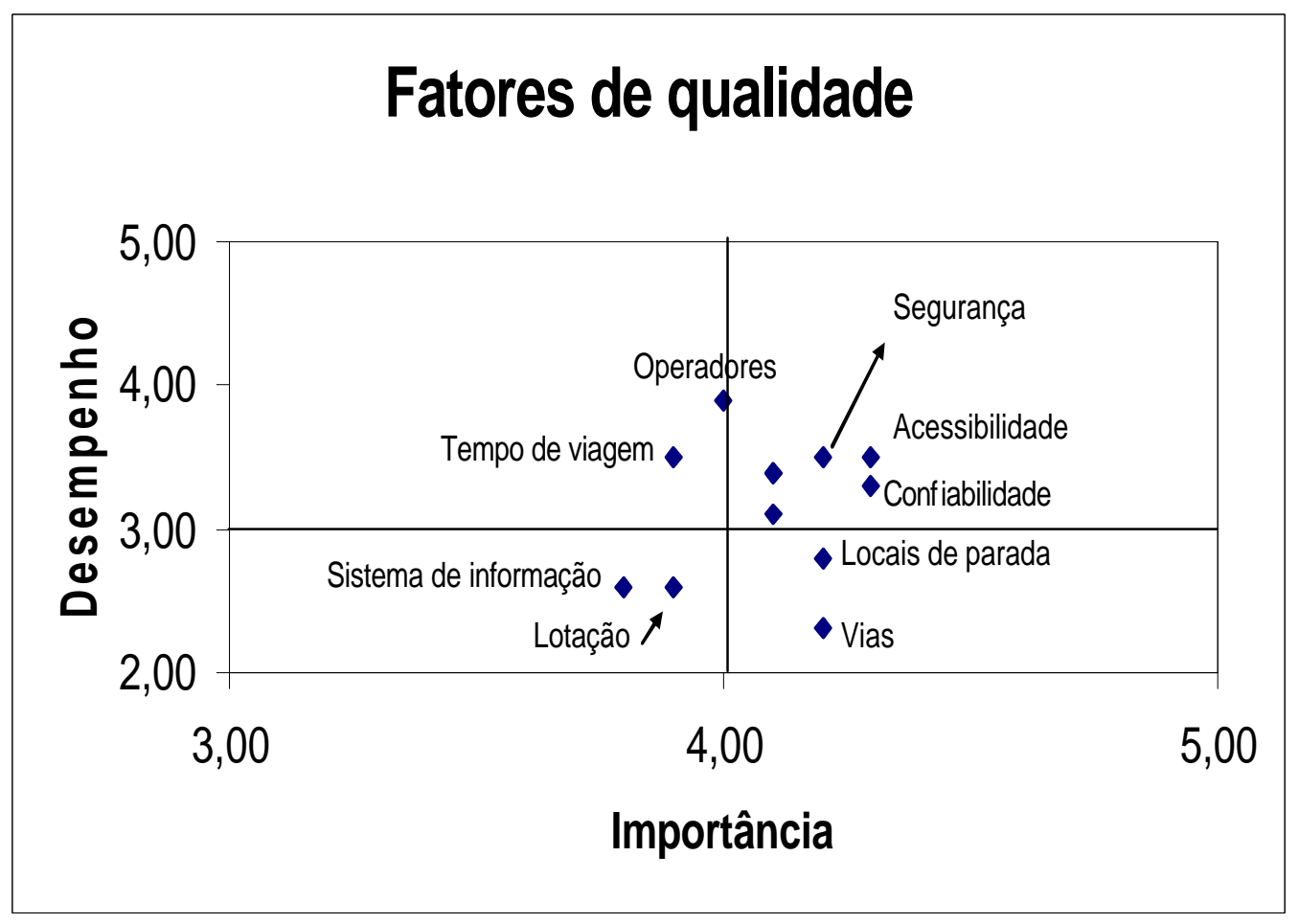

Figura 4.4 - Desempenho x Importância dos fatores de qualidade para o segmento "trabalhador"

Essa metodologia pode ser aplicada para as demais categorias de usuários do sistema passageiros comuns, estudantes e idosos/deficientes - com objetivo de mapear as opiniões e identificar os problemas específicos facilitando o planejamento de ações focadas por segmento de usuários. 


\section{5}

\section{CONCLUSÕES}

Os resultados globais da pesquisa de campo apontam que os fatores estado das vias, características dos locais de parada e lotação tem grande importância para os usuários e não estão bem avaliados. A seguir são colocadas as principais ações propostas para a melhoria desses fatores.

Quanto ao estado das vias espera-se um plano de recuperação e redimensionamento do pavimento das ruas por onde circulam os coletivos, inclusive com suavização das valetas e lombadas existentes ao longo dos itinerários. A sinalização vertical e horizontal dessas vias também deve ser recuperada e revista, com priorização sempre que possível do deslocamento dos coletivos em relação aos demais veículos.

Quanto aos locais de parada deve-se instalar uma quantidade maior de abrigos com bancos, não apenas na região central, mas nos bairros onde os usuários aguardam para se dirigir ao centro da cidade, que é o principal pólo de atração de viagens. Nos bairros é necessária maior utilização de sinalização indicativa de pontos de embarque, facilitando a entrada dos usuários no sistema. Em todos os pontos devem ser disponibilizadas informações aos usuários quanto a horários e linhas que passam pelo local.

Quanto ao fator lotação, a empresa operadora deve disponibilizar mais veículos, principalmente nos horários de pico, possibilitando menores níveis de lotação. Um 
reestudo do traçado das linhas atuais também se faz necessário por parte da gerenciadora do sistema, pois em alguns horários existe sobrecarga de passageiros em determinadas linhas e ociosidade em outras.

Considerando os resultados obtidos com os usuários da linha 2, além de estados das vias e lotação aparece um outro fator como crítico, a frequiência. A melhoria nesse caso pode ser alcançada com um aumento no número de veículos alocados na linha, diminuindo o intervalo entre atendimentos, e amenizando os níveis de lotação.

Os trabalhadores consideram como itens de maior importância a confiabilidade e acessibilidade, esses dados parecem ser coerentes com a categoria profissional pesquisada, uma vez que, para o trabalhador, chegar e, se possível, na hora certa ao trabalho é essencial para a manutenção de seu emprego.

É necessário ampliar a valorização dos resultados das pesquisas de opinião, contrapondo-se a supremacia dos dados técnicos que, isoladamente, proporcionam uma visão distorcida da complexa relação existente entre usuários e serviços de transporte.

Para a gestão da qualidade atingir plenamente seus propósitos, terá cada vez mais que compatibilizar os parâmetros técnicos que visam atender as especificações do contrato e tem forte repercussão nos custos, com as necessidades e expectativas dos clientes. As opiniões, necessidades e expectativas dos clientes tornam-se indispensáveis à gestão, pois servem de entradas para a melhoria da qualidade e redirecionamento orçamentário.

Além disso, tem-se a necessidade de um tratamento integrado da questão no contexto do planejamento urbano, equacionando o transporte com o uso e ocupação do solo e promovendo ações articuladas com a operação do sistema viário e as intervenções da engenharia de tráfego.

Apesar da hierarquização, o grau de importância atribuída - ou importância declarada é bastante elevado para todas as características de serviço analisadas: as médias variam de 3,5 a 4,3 em uma escala de 1 a 5. Assim o fator apontado como menos importante (tempo de viagem) não está tão distante daquele apontado como mais importante 
(acessibilidade e segurança), nesse sentido é fundamental aprofundar a análise da importância dos atributos.

É relevante notar que as avaliações realizadas pela Prefeitura Municipal e por técnicos sinalizam uma qualidade do serviço superior àquela obtida na pesquisa com os usuários.

Finalmente, vale ressaltar que os resultados aqui expostos justificam os métodos e processos sugeridos, contudo o aproveitamento dos resultados deve respeitar as características de cada local ou momento de análise. 


\section{6}

\section{BIBLIOGRAFIA}

AGUIAR, E. M. (1985). Análise crítica dos indicadores de eficiência e eficácia propostos para avaliação de sistemas de transporte público urbano. São Carlos. Dissertação (Mestrado) - Escola de Engenharia de São Carlos, Universidade de São Paulo.

ASSOCIAÇÃO NACIONAL DOS TRANSPORTES PUBLICOS (1995). A opinião do usuário como indicador de qualidade. Revista dos Transportes Públicos, n. 67.

ASSOCIAÇÃO NACIONAL DOS TRANSPORTES PUBLICOS (1997). Transporte humano: cidades com qualidade de vida. São Paulo.

ASSIS, M. F. (1987). Avaliação do desempenho e adequação de sistemas de transporte público, por ônibus, de cidades de porte médio em relação a sua estrutura urbana. São Carlos. Dissertação (Mestrado) - Escola de Engenharia de São Carlos, Universidade de São Paulo.

BRASSARD, M. (1985). Ferramentas para uma melhoria contínua. Rio de Janeiro, Qualitymark.

BROCKA, B.; BROCKA M. S. (1994). Gerenciamento da qualidade. São Paulo, Makron Books.

CAMPOS, V. F. (1992). TQC controle da qualidade total (no estilo japonês). Belo Horizonte, Fundação Christiano Ottoni. 
EMPRESA BRASILEIRA DOS TRANSPORTES URBANOS - EBTU (1986). Planejamento da operação. Elementos intervenientes. vol. 2.

FARIA, C. A. (1985). Percepção do usuário com relação às características do nível de serviço do transporte coletivo urbano por ônibus. São Carlos. Dissertação (Mestrado) Escola de Engenharia de São Carlos, Universidade de São Paulo.

FERRARI, H. S. (2001). Racionalização da operação numa empresa de transporte por fretamento. São Carlos. Dissertação (Mestrado) - Escola de Engenharia de São Carlos, Universidade de São Paulo.

FERRAZ, A. C. P. (1988). A qualidade do serviço de transporte coletivo em cidades médias sob a ótica dos usuários. II CONGRESSO DA ASSOCIAÇÃO NACIONAL DE ENSINO E PESQUISA EM TRANSPORTES - ANPET São Paulo, Anais vol. 1, pp 111-126.

FERRAZ, A. C. P. (1990). Sobre a eficiência e a eficácia do transporte publico nas cidades médias. São Carlos, Tese (Livre-docência) - Escola de Engenharia de São Carlos, Universidade de São Paulo.

FERRAZ, A. C. P. (1998). Escritos sobre transporte, trânsito e urbanismo. Ribeirão Preto, São Francisco.

FERRAZ, A. C. P.; TORRES, I. G. E. (2004). Transporte Público Urbano. 2a . ed. São Carlos, Rima.

KAW MOTO, E. (1984). Custo e nível de serviço no transporte público por ônibus. São Carlos, Dissertação (Mestrado) - Escola de Engenharia de São Carlos, Universidade de São Paulo.

KAWAMOTO, E. (1987). Um novo enfoque do processo de escolha em transporte com tratamento baseado na psicofísica multidimensional. São Carlos, Tese (Doutorado) - Escola de Engenharia de São Carlos, Universidade de São Paulo.

LIMA JR., O. F. (1995). Qualidade em serviços de transportes: conceituação e procedimento para diagnóstico. São Paulo, Tese (Doutorado) - Escola Politécnica, Universidade de São Paulo.

LIMA, I. O. (1996). O novo e o velho na gestão da qualidade do transporte urbano. $1^{\text {a }}$. ed. São Paulo, Edições Profissionais. 
MBB - MERCEDES BENZ DO BRASIL S. A. (1987). Sistema de transporte coletivo urbano por ônibus - planejamento e operação. São Bernardo do Campo.

NETO, A. A. A. R. (2001). Contribuição a avaliação de transporte urbano por ônibus. São Carlos, Dissertação (Mestrado) - Escola de Engenharia de São Carlos, Universidade de São Paulo.

PREFEITURA MUNICIPAL DE SÃO CARLOS (2003). Contrato de concessão para prestação e exploração de serviços de transporte coletivo de passageiros.

PREFEITURA MUNICIPAL DE SÃO CARLOS (2004). Relatório do Sistema de Avaliação da Qualidade do Serviço de Transporte Coletivo de São Carlos.

PREFEITURA MUNICIPAL DE SÃO CARLOS (2005). Relatório do Sistema de Avaliação da Qualidade do Serviço de Transporte Coletivo de São Carlos.

PREFEITURA MUNICIPAL DE SÃO CARLOS (2005). São Carlos: Portal do Cidadão. Apresenta dados geográficos e demográficos. Disponível em:<http:/www.saocarlos.sp.gov.br> Acesso em: 07 ago.

PRODESP (2005). Companhia de Processamento de Dados do Estado de São Paulo. Disponível em<http:/www.prodesp.sp.gov.br> Acesso em 16 set.

SANCHEZ, S. P. (1988). Contribuição á análise operacional de redes de transporte coletivo em cidades de porte médio. São Carlos, Dissertação (Mestrado) - Escola de Engenharia de São Carlos, Universidade de São Paulo.

SILVA, A. N. R. (1993). O custo do solo urbano ocioso e uma nova sistemática de tributação da propriedade. São Carlos, Tese (Doutorado) - Escola de Engenharia de São Carlos, Universidade de São Paulo.

SPINELLI, L. B. (1999). Padrões de qualidade para o transporte público por ônibus nas cidades de porte médio. São Carlos, Dissertação (Mestrado) - Escola de Engenharia de São Carlos, Universidade de São Paulo.

TRAVASSOS, G. (2005). Peculiaridades que condicionam ações de marketing nos transportes públicos por ônibus. Revista dos Transportes Públicos - ANTP. São Paulo, $\mathrm{n}^{\mathrm{o}} .105, \mathrm{pp} .33-50$. 
TIRONI, L. F.; SILVA, L. C. E.; VIANA, L. M.; MEDICI, A. C. (1991). Critérios para a geração de indicadores de qualidade e produtividade no serviço público. IPEA textos para discussão interna. Brasília.

VASCONCELLOS, E. A. (1996). Transporte urbano nos países em desenvolvimento: reflexões e propostas. 1 ed. São Paulo, Editoras Unidas Ltda.

VUCHIC, V. R. (2000). Transportation for livable cities. Center for Urban Policy Research. New Jersey, EUA.

WAISMAN, J. (1983). Avaliação do desempenho de sistemas de ônibus, em cidades de porte médio, em função de sua produtividade, eficiência operacional e qualidade dos serviços. São Carlos, Tese (Doutorado) - Escola de Engenharia de São Carlos, Universidade de São Paulo. 


\section{7}

\section{APÊNDICES}

\section{Apêndice A - Relação das viagens especiais em um dia útil}

ESP. 01

06:15 - JÓQUEI CLUBE X REDENÇÃO - VIA PAULISTANO-MARGINAL 06:35 - REDENÇÃO X SESI - VIA BELA VISTA

07:40 - CIDADE ARACY X UFSCar - VIA PRAÇA ITÁLIA ATÉ ÁREA NORTE

ESP. 02

06:00 - ANTENOR GARCIA X MARIA STELLA FAGÁ - VIA PRAÇA ITÁLIA

07:20 - MARIA STELLA FAGÁ X UFSCar ATÉ ÁREA NORTE

11:00 - ESTAÇÃO X RESIDENCIAL SAMAMBAIA

11:50 - UFSCar [ÁREA NORTE] X MARIA STELLA FAGÁ - VIA RUA XV

12:45 - RESIDENCIAL SAMAMBAIA X ESTAÇÃO

13:20 - MARIA STELLA FAGÁ X UFSCar ATÉ ÁREA NORTE

ESP. 03

06:05 - VARJÃO X SESI - VIA SAMAMBAIA - PRAÇA ITÁLIA ATÉ DI FATO

07:15 - CIDADE ARACY X SANTA CASA - VIA BELA VISTA

11:55 - ESTAÇÃO X SANTA FELÍCIA - VIA SANTA CASA

12:25 - SANTA FELÍCIA X ESTAÇÃO - VIA SANTA CASA

13:20 - REDENÇÃO X UFSCar - VIA BOTAFOGO ATÉ ÁREA NORTE

ESP. 04

05:25 - ANTENOR GARCIA X JÓQUEI CLUBE - VIA PRAÇA ITÁLIA ATÉ ARACÊ 06:10 - (ARACÊ) STA FELICIA X CID. ARACY - VIA SANTA CASA - BELA VISTA

07:05 - CID. ARACY X V. SÃO JOSÉ - P. ITÁLIA - ROD. - C. D'ÁGUA - C. SAÚDE

12:30 - CRUZEIRO DO SUL X SANTA CASA - VIA BELA VISTA - ATÉ ARACÊ

13:10 - ARACÊ DE SANTO ANTONIO X ESTAÇÃO - VIA SANTA FELÍCIA - SANTA CASA 


\section{ESP. 05}

06:30 - ASTOLPHO LUIZ DO PRADO X ESTAÇÃO - VIA RUA CONDE DO PINHAL 07:25 - ESTAÇ̃̃O X UFSCar - VIA SANTA CASA - CID. JARDIM ATÉ ÁREA NORTE 12:05 - ESTAÇÃO X MARIA STELLA FAGÁ - VIA RUA XV DE NOVEMBRO 12:40 - MARIA STELLA FAGÁ X ESTAÇÃO - VIA RUA CONDE DO PINHAL 13:25 - ESTAÇÃO X UFSCar - VIA SANTA CASA - CID. JARDIM ATÉ ÁREA NORTE

ESP. 06

06:25 - CRUZEIRO DO SUL X SANTA CASA - VIA BELA VISTA ATÉ ESC. CEFAM 07:15 - BOTAFOGO X UFSCar - VIA REDENÇÃO - BOTAFOGO

\section{ESP. 07}

06:10 - SANTA FELICIA X SESI - VIA SINDICATO - SANTA CASA - BELA VISTA

07:00 - CIDADE ARACY X UFSCar - VIA BELA VISTA ATÉ ÁREA NORTE

ESP. 08

06:10 - VILA SÃO JOSÉ X FÁBRICA SILTOMAC - VIA RODOVIÁRIA - BELA VISTA 07:20 - JÓQUEI CLUBE X ESTAÇÃO - VIA CEMITÉRIO

07:40 - ESTAÇÃO X UFSCar - ÁREA NORTE ATÉ O SAMAMBAIA

ESP. 09

05:45 - ANT. GARCIA X ST ${ }^{\mathrm{A}}$ FELICIA - VIA B. VISTA - SHOPPING - ST ${ }^{\mathrm{a}}$ CASA-ASSER 06:30 - SANTA FELICIA X BELA VISTA - VIA SINDICATO - RODOVIÁRIA

07:25 - CIDADE ARACY X SANTA FELICIA - VIA C.COMUNITÁRIO - SANTA CASA 08:25 - SANTA FELÍCIA X ESTAÇÃO - VIA SANTA CASA

ESP. 10

06:25 - CIDADE ARACY X SANTA FELICIA - VIA C. COMUNITÁRIO - SANTA CASA 07:25 - SANTA FELICIA X ESTAÇÃO - VIA SANTA CASA

ESP. 11

06:00 - MARIA S. FAGÁ [ITAMARATI] X SESI - VIA BELA VISTA ATÉ A DI SOLO 07:20 - MARIA S. FAGÁ X ST ${ }^{A}$ FELICIA - VIA RODOV. - ST ${ }^{A}$ CASA E ATÉ PROHAB

ESP. 12

06:05 - SANTA FELICIA X SESI - VIA SINDICATO - SANTA CASA - BELA VISTA

07:15 - CIDADE ARACY X SANTA CASA - VIA BELA VISTA ATÉ O SHOPPING

ESP. 13

06:20 - JARDIM BELVEDERE X VILA NERY - VIA BOTAFOGO

07:15 - SANTA FELICIA X ESTAÇÃO - VIA SINDICATO - SANTA CASA

07:50 - ESTAÇÃO X UFSCar - ATÉ ÁREA NORTE

12:05 - CENTRO X ANTENOR GARCIA - VIA PRAÇA ITALIA

12:45 - ANTENOR GARCIA X UFSCar - VIA PRAÇA ITALIA - ATÉ ÁREA NORTE

ESP. 14

06:15 - CIDADE ARACY X SANTA FELICIA - VIA BELA VISTA - SANTA CASA

07:10 - SANTA FELICIA X SESI - VIA SANTA CASA - RUA LARGA

ESP. 15

06:00 - SANTA FELICIA X C.E.A.T. - VIA RODOVIÁRIA - BOTAFOGO

07:00 - CIDADE ARACY X UFSCar - VIA PRAÇA ITÁLIA ATÉ ÁREA NORTE

11:30 - SESI X ANTENOR GARCIA - VIA PRAÇA ITALIA

12:20 - ANTENOR GARCIA X SESI - VIA PRAÇA ITALIA

13:25 - CRUZEIRO DO SUL X UFSCar - VIA BELA VISTA - ATÉ ÁREA NORTE 


\section{ESP. 16}

06:45 - ANTENOR GARCIA X SANTA FELICIA - VIA PRAÇA ITÁLIA - SANTA CASA

07:45 - SANTA FELICIA X ESTAÇÃO - VIA SANTA CASA

12:15 - MARIA STELLA FAGÁ X SESI - VIA RUA CONDE DO PINHAL

ESP. 17

06:15 - ANTENOR GARCIA X SANTA FELICIA - VIA BELA VISTA - SANTA CASA

07:20 - SANTA FELICIA X UFSCar - VIA CIDADE JARDIM ATÉ ÁREA NORTE

\section{ESP. 18}

06:05 - CIDADE ARACY II X SANTA CASA - VIA PRAÇA ITÁLIA

06:45 - ST ${ }^{A}$ FELICIA X BELA VISTA - VIA ST ${ }^{A}$ CASA - RUA LARGA - BERNASCONI

07:55 - MARA STELLA FAGÁ X SANTA CASA - VIA VILA MONTEIRO

11:40 - ESTAÇÃO X SANTA FELÍCIA - VIA SANTA CASA

12:10 - SANTA FELÍCIA X SESI - VIA SINDICATO - SANTA CASA - PRAÇA ITÁLIA

ESP. 19

06:10 - PARQUE FEHR X CIDADE ARACY - VIA SANTA CASA

07:05 - ARACY II X VILA SÃO JOSÉ - VIA P. ITÁLIA - ROD. - C.D’ÁGUA - C. SAÚDE

ESP. 20

06:30 - R. TORTORELLI X ESTAÇÃO - VIA SANTA CASA

07:25 - BOTAFOGO X MARIA STELLA FAGÁ - VIA MEDEIROS - RODOVIÁRIA

ESP. 21

05:55 - ANTENOR GARCIA X JÓQUEI CLUBE - VIA PRAÇA ITÁLIA

07:30 - MARIA STELLA FAGÁ X ESTAÇÃO - VIA RODOVIÁRIA

ESP. 22

05:50 - CIDADE ARACY X UFSCar - VIA PRAÇA ITÁLIA ATÉ ÁREA NORTE

07:20 - CIDADE ARACY X UFSCar - VIA PRAÇA ITÁLIA ATÉ ÁREA NORTE

11:20 - ESCOLA SEBASTIÃO OLIVEIRA ROCHA X SANTA FELICIA

12:25 - SANTA FELICIA X ESTAÇÃO - VIA SANTA CASA

ESP. 23

06:05 - CIDADE ARACY II X SESI - VIA PRAÇA ITÁLIA

06:55 - MARIA STELLA FAGÁ X SANTA CASA - VIA VILA MONTEIRO

11:50 - MERCADO X CIDADE ARACY - VIA CENTRO COMUNITÁRIO

13:00 - REDENÇÃO X JÓQUEI CLUBE - VIA BOTAFOGO - CEMITÉRIO

\section{ESP. 24}

06:10 - ANTENOR GARCIA X SESI - VIA PRAÇA ITÁLIA

07:20 - ANT. GARCIA X ST ${ }^{A}$ FELICIA - VIA BELA VISTA - ST ${ }^{A}$ CASA - SINDICATO

12:25 - ESTAÇÃO X JÓQUEI CLUBE - VIA CEMITÉRIO

ESP. 25

06:20 - SÃO CARLOS (ESTAÇÃO) X TAM

07:25 - AZULVILLE X UFSCar - VIA AV.GET VARGAS - ÁREA NORTE

ESP. 26

06:45 - ANTENOR GARCIA X UFSCAR (ÁREA SUL) - VIA PRAÇA ITÁLIA

07:45 - ANTENOR GARCIA X SANTA CASA - VIA PRAÇA ITÁLIA 


\section{ESP. 27}

06:25 - ASTOLPHO LUIZ DO PRADO X ESTAÇÃO - VIA RODOVIÁRIA

07:00 - ESTAÇÃO X RESIDENCIAL SAMAMBAIA

07:20 - RESIDENCIAL SAMAMBAIA X ESTAÇÃO

07:50 - ROMEU TORTORELLI X ESTAÇÃO - VIA SANTA CASA

\section{ESP. 28}

06:25 - SANTA FELICIA X ESTAÇÃO - VIA SANTA CASA

07:15 - ANTENOR GARCIA X SANTA CASA - VIA BELA VISTA

\section{ESP. 29}

06:15 - SÃO CARLOS X TAM - VIA ÁGUA VERMELHA

06:55 - TAM X SÃO CARLOS

07:30 - ESTAÇÃO X UFSCar - VIA SANTA CASA - CID. JARDIM - ATÉ ÁREA NORTE

ESP. 30

16:35 - PREFEITURA X CIDADE ARACY - VIA C. COMUNITÁRIO-ATÉ ANTENOR GARCIA 17:50 - ESTAÇÃO X MARIA STELLA FAGÁ - VIA RODOVIÁRIA

ESP. 31

16:30 - RESIDENCIAL SAMAMBAIA X ESTAÇÃO

17:15 - ENGEMASA X JÓQUEI CLUBE - VIA PRAÇA ITÁLIA

17:50 - UFSCar [ÁREA NORTE] X MARIA STELLA FAGÁ - VIA RUA XV DE NOVEMBRO

ESP. 32

16:55 - UFSCar [ÁREA SUL]/PQ ECOLÓGICO X ANTENOR GARCIA - VIA BELA VISTA

17:55 - ESCOLA JESUINO DE ARRUDA X SANTA FELICIA - VIA SANTA CASA-ATÉ P. FEHR

ESP. 33

15:35 - TREVO X CIDADE ARACY - VIA CENTRO COMUNITÁRIO

16:45 - ESTAÇÃO X SANTA FELICIA - VIA SANTA CASA

17:55 - ESC. SEBASTIÃO O. ROCHA X CIDADE ARACY - VIA BELA VISTA

ESP. 34

17:10 - JÓQUEI CLUBE UFSCar-[ÁREA NORTE] X ANTENOR GARCIA - VIA PRAÇA ITÁLIA

18:10 - CIDADE ARACY X MARIA STELLA FAGÁ - VIA PRAÇA ITÁLIA - RODOVIÁRIA

ESP. 35

16:50 - UFSCar [ÁREA SUL] X CIDADE ARACY - VIA BELA VISTA

17:45 - CIDADE ARACY X JÓQUEI CLUBE - VIA PRAÇA ITÁLIA

18:20 - JÓQUEI CLUBE X BELA VISTA - VIA ESTAÇÃO NORTE

\section{ESP. 36}

17:05 - J. MARACANÃ [DI SOLO] X SANTA MARIA - VIA SESI - P. ITÁLIA

18:15 - ESTAÇÃO X RESIDENCIAL SAMAMBAIA

18:40 - RESIDENCIAL SAMAMBAIA X ESTAÇÃO

ESP. 37

16:45 - SANTA FELICIA X MARIA STELLA FAGÁ - VIA ESCOLA CEFAM - RODOVIÁRIA

17:45 - JÓQUEI CLUBE X CIDADE ARACY - VIA BELA VISTA

18:30 - CIDADE ARACY X UFSCar - VIA PRAÇA ITÁLIA ATÉ ÁREA NORTE

\section{ESP. 38}

15:50 - ESTAÇÃO X SANTA FELICIA - VIA SANTA CASA ATÉ ARNON DE MELLO

17:15 - UFSCar [ÁREA SUL] X AZULVILLE - VIA VILA MONTEIRO

17:55 - AZULVILLE X SANTA MARIA - VIA PRAÇA ITÁLIA 
ESP. 39

16:10 - GARAGEM X CIDADE ARACY - VIA AEROPORTO - PRAÇA ITÁLIA

17:25 - MARIA STELLA FAGÁ X SANTA FELICIA - VIA VILA MARCELINO - SANTA CASA

18:25 - SANTA FELICIA X BELA VISTA - VIA SANTA CASA

ESP. 40

16:20 - JÓQUEI CLUBE X CIDADE ARACY II - VIA PRAÇA ITÁLIA

17:15 - ELECTROLUX X MARIA STELLA FAGÁ - VIA MAJOR

18:10 - UFSCar [ÁREA NORTE] X PACAEMBÚ - VIA BELA VISTA

ESP. 41

16:00 - MARIA STELLA FAGÁ X J. MARACANÃ - VIA RODOVIÁRIA - BELA VISTA

17:05 - J.MARACANÃ[DI SOLO] X VILA NERY - VIA BELA VISTA - RUA XV DE NOVEMBRO

17:40 - VILA NERY X CIDADE ARACY - VIA Av. Dr. CARLOS BOTELHO - C. COMUNITÁRIO

18:25 - CIDADE ARACY X SANTA FELICIA - VIA C.COMUNITÁRIO - SANTA CASA ASSER

\section{ESP.42}

17:00 - J. SÃO RAFAEL X ANTENOR GARCIA - VIA RODOVIÁRIA - PRAÇA ITÁLIA

18:20 - ANTENOR GARCIA X SANTA FELICIA - VIA BELA VISTA - RODOVIÁRIA

ESP. 43

16:00 - SANTA CASA X MARIA STELLA FAGÁ - VIA RODOVIÁRIA

17:15 - C.E.A.T. X SANTA FELICIA - VIA BOTAFOGO - RODOVIÁRIA ATÉ ARNON DE MELLO

ESP. 44

15:00 - UFSCar [ÁREA SUL] X ANTENOR GARCIA - VIA PRAÇA ITÁLIA

17:20 - PREFEITURA UFSCar [ÁREA SUL]X SANTA FELICIA VIA CID. JARDIM

18:15 - VILA SÃO JOSÉ X CIDADE ARACY II - VIA PRAÇA ITÁLIA ATÉ CAIXA D’ÁGUA

ESP. 45

17:05 - SESI [FABRICAS] X SANTA FELICIA - VIA PRAÇA ITÁLIA - SANTA CASA -

18:00 - UFSCar [ÁREA NORTE] X CIDADE ARACY - VIA BELA VISTA ATÉ CAIXA D'ÁGUA

\section{ESP. 46}

16:55 - UFSCar (ÁREA NORTE) X ANTENOR GARCIA - VIA PRAÇA ITÁLIA

17:50 - ANTENOR GARCIA X MARIA STELLA FAGÁ - VIA PRAÇA ITÁLIA - MAJOR

18:40 - MARIA STELLA FAGÁ X ESCOLA JULIANO NETO

ESP. 47

16:50 - ESTAÇÃO X MARIA STELLA FAGÁ - VIA RODOVIÁRIA

17:40 - UFSCar [ÁREA NORTE] X AZULVILLE - VIA VILA MONTEIRO

18:25 - AZULVILLE X UFSCar - VIA AV. GETÚLIOVARGAS - VILA MONTEIRO

ESP. 48

16:00 - SANTA CASA X ANTENOR GARCIA - VIA PRAÇA ITÁLIA

17:10 - J.MARACANÃ [DI SOLO] X SANTA FELICIA - VIA BELA VISTA - SANTA CASA

18:25 - SANTA FELICIA X VILA NERY ATÉ ESCOLA ESTERINA PLACCO

ESP. 49

17:05 - SESI [FABRICAS] X ANTENOR GARCIA - VIA PRAÇA ITÁLIA

18:10 - ESTAÇÃO X SANTA FELICIA - VIA SANTA CASA ATÉ ARACÊ DE SANTO ANTONIO

19:00 - ARACÊ DE SANTO ANTONIO X ESTAÇÃO VIA SANTA FELICIA - SANTA CASA

ESP. 50

16:35 - UFSCar (ÁREA SUL) X SANTA FELICIA - VIA AEROPORTO - CIDADE JARDIM

17:00 - ESCOLA CEFAM X CIDADE ARACY - VIA BELA VISTA

18:15 - CENTRO X ANTE NOR GARCIA - VIA PRAÇA ITÁLIA 


\section{ESP. 51}

16:15 - SÃO CARLOS X TAM - VIA ÁGUA VERMELHA - TREVO JD. PAULISTANO

17:10 - TAM X SÃO CARLOS - VIA ÁGUA VERMELHA

\section{ESP.52}

16:35 - PRAÇA XV (EMBRAPA) X ANTENOR GARCIA - VIA BELA VISTA

17:45 - CENTRO X ANTENOR GARCIA - VIA BELA VISTA

\section{ESP.53}

16:45 - TAM X SÃO CARLOS - VIA TREVO JD. PAULISTANO - ESTAÇÃO NORTE 17:20 - ESTAÇÃO X DOURADINHO - VIA MAJOR

\section{ESP.54}

23:30 - SHOPPING IGUATEMI X MARIA STELLA FAGÁ - VIA SESC - ESTAÇÃO NORTE -

23:30 - SHOPPING IGUATEMI X CIDADE ARACY - VIA BELA VISTA - REP. LÍBANO

23:30 - SHOPPING IGUATEMI X JÓQUEI CLUBE - ROMA - ARNON DE MELLO

22:35 - UFSCAR [AREA NÓRTE] X CIDADE ARACY - VIA PRAÇA ITÁLIA

22:35 - UFSCAR [AREA NORTE] - INDUSTRIAL - MILITÃO X SANTA FELÍCIA

22:35 - JD. D. FRANCISCA X SANTA.FELICIA VIA E. ASSER - ARL. BITTENCOURT

22:40 - ESCOLA MILITÃO DE LIMA - JULIANO NETO X MARIA STELLA FAGÁ

23:10 - ESCOLA JESUÍNO DE ARRUDA X SANTA FELÍCIA - VIA BELA VISTA - SANTA CASA 


\section{Apêndice B - Formulário de pesquisa}

\section{PESQUISA COM USUÁRIO}

LINHA:

SENTIDO: HORÁRIO:

TIPO CLIENTE:

COMUM_ TRABALHADOR_ ESTUDANTE _ IDOSO_ DEFICIENTE_

\section{ITEM AVALIADO:}

ACESSIBILIDADE: QUANTO Á DISTÂNCIA DE CAMINHADA ATÉ O PONTO DE ÔNIBUS... GRAU DE SATISFAÇÃO GRAU DE IMPORTÂNCIA

FREQÜÊNCIA: QUANTO AO INTERVALO ENTRE DOIS ÔNIBUS DA MESMA LINHA... GRAU DE SATISFAÇÃO GRAU DE IMPORTÂNCIA

TEMPO DE VIAGEM: QUANTO A DURAÇÃO DA VIAGEM DENTRO DO ÔNIBUS... GRAU DE SATISFAÇÃO GRAU DE IMPORTÂNCIA

LOTAÇÃO: QUANTO A LOTAÇÃO DOS ÔNIBUS... GRAU DE SATISFAÇÃO GRAU DE IMPORTÂNCIA CONFIABILIDADE: QUANTO A PONTUALIDADE DOS ÔNIBUS... GRAU DE SATISFAÇÃO GRAU DE IMPORTÂNCIA

SEGURANÇA: QUANTO AOS ACIDENTES/ASSALTOS ENVOLVENDO ÔNIBUS... GRAU DE SATISFAÇÃO GRAU DE IMPORTÂNCIA

CARACTERÍSTICAS DOS VEÍCULOS: QUANTO AO CONFORTO DOS ÔNIBUS... GRAU DE SATISFAÇÃO GRAU DE IMPORTÂNCIA

CARACTERÍSTICAS DOS LOCAIS DE PARADA: QUANTO AOS PONTOS DE ÔNIBUS... GRAU DE SATISFAÇÃO GRAU DE IMPORTÂNCIA

SISTEMA DE INFORMAÇÃO: QUANTO AO NÍVEL DE INFORMAÇÃO AOS USUÁRIOS... GRAU DE SATISFAÇÃO GRAU DE IMPORTÂNCIA

CONECTIVIDADE: QUANTO A INTEGRAÇÃO DAS LINHAS...

GRAU DE SATISFAÇÃ̃O

GRAU DE IMPORTÂNCIA

OPERADORES: QUANTO AO COMPORTAMENTO DO MOTORISTA E DO COBRADOR... GRAU DE SATISFAÇÃO GRAU DE IMPORTÂNCIA

VIAS: QUANTO AS CONDIÇÕES DAS RUAS POR ONDE TRAFEGAM OS ÔNIBUS... GRAU DE SATISFAÇÃO GRAU DE IMPORTÂNCIA

\section{GRAU DE SATISFAÇÃO}

\section{GRAU DE IMPORTÂNCIA}

5 ÓTIMO

4 BOM

5 EXTREMAMENTE IMPORTANTE

3 REGULAR

4 IMPORTANTE

2 RUIM

3 MÉDIA IMPORTÂNCIA

1 PÉSSIMO

2 BAIXA IMPORTÂNCIA

1 NENHUMA IMPORTÂNCIA

OBS: 
Apêndice C - Avaliações dos fatores de qualidade do transporte coletivo de São Carlos
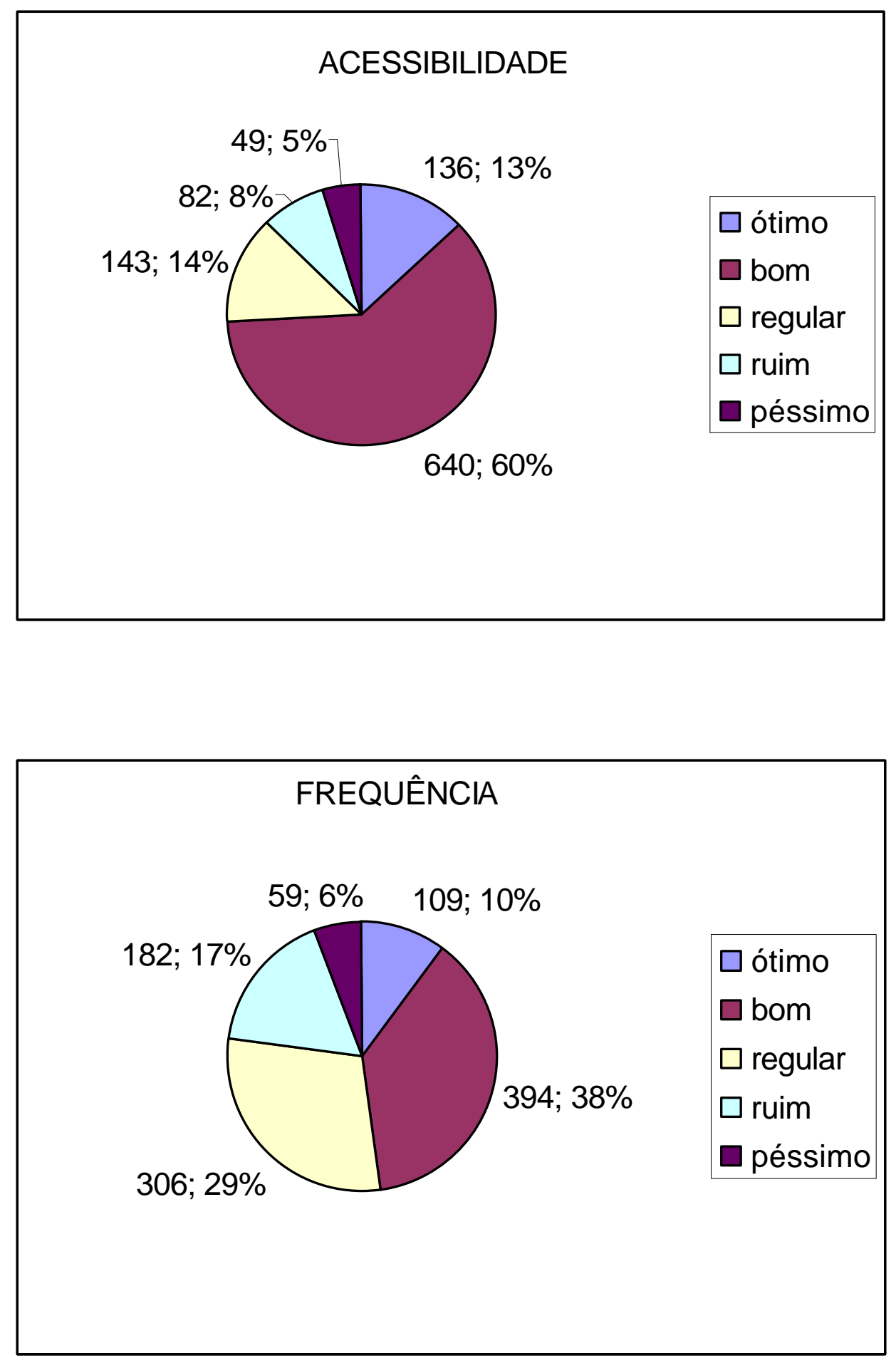

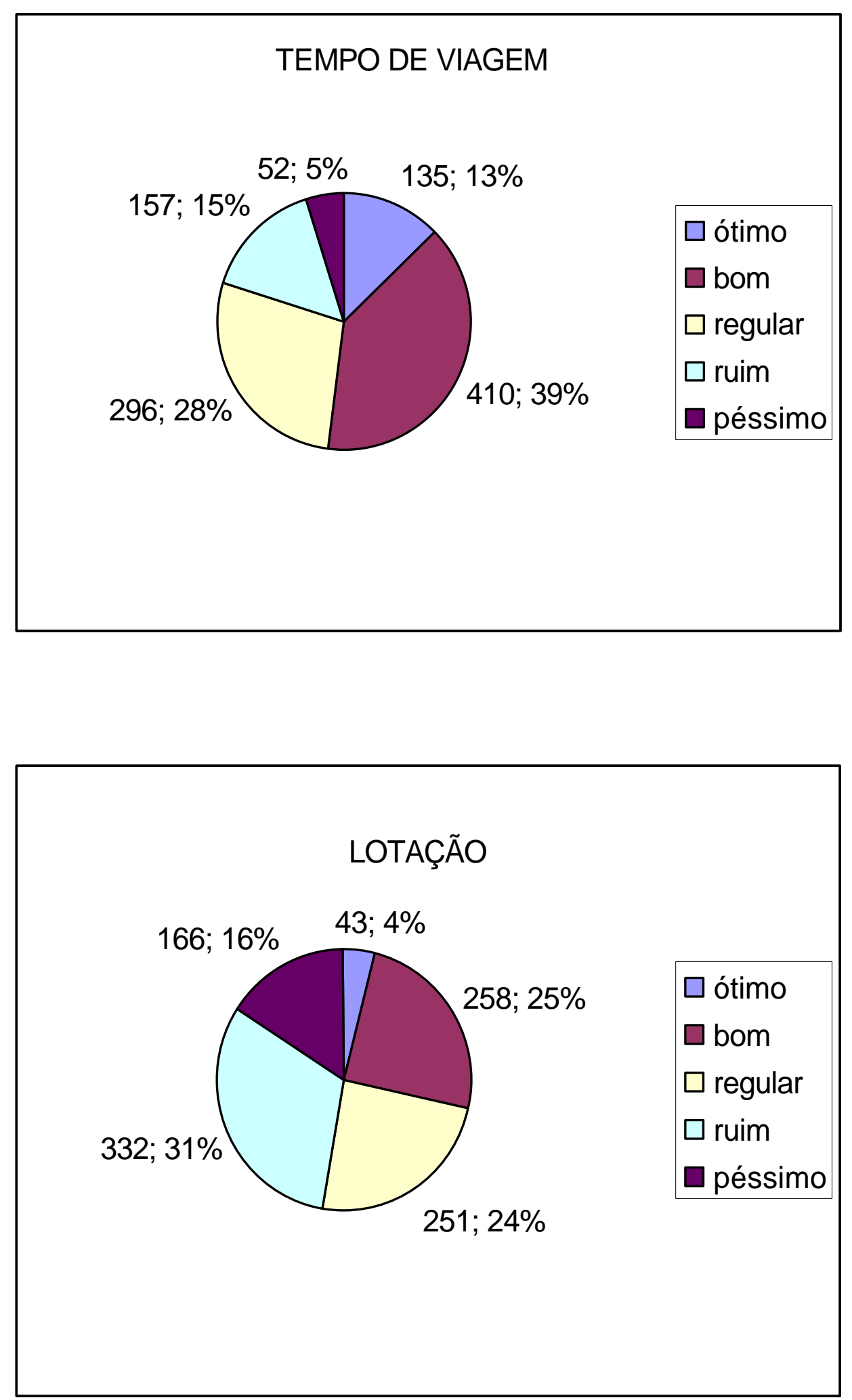

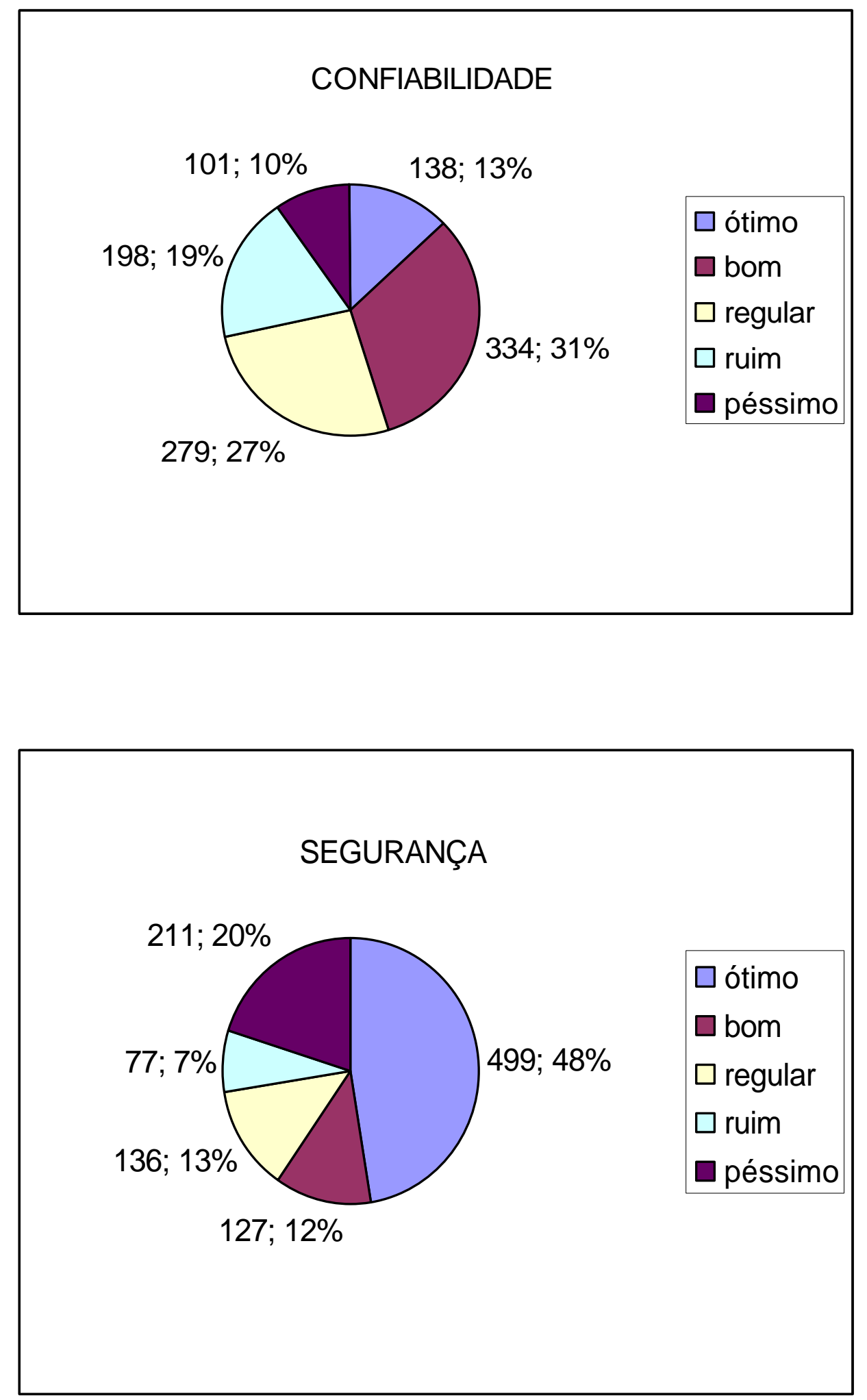


\section{CARACTERÍSTICAS DOS VEÍCULOS}

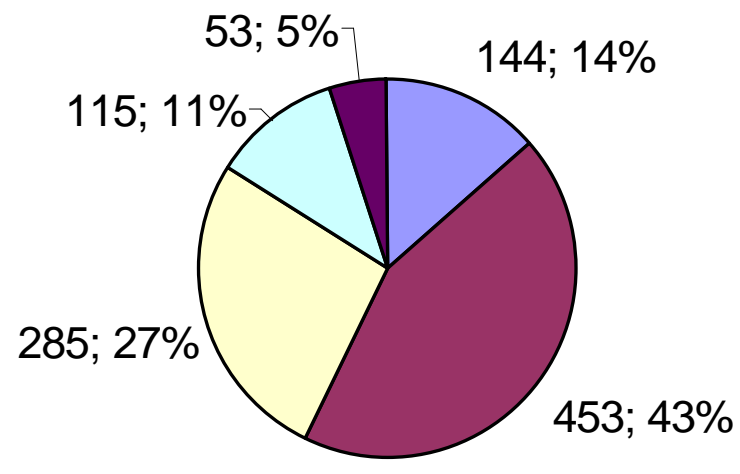

$\square$ ótimo

$\square$ bom

$\square$ regular

$\square$ ruim

$\square$ péssimo

CARACTERÍSTICAS DOS LOCAIS DE PARADA

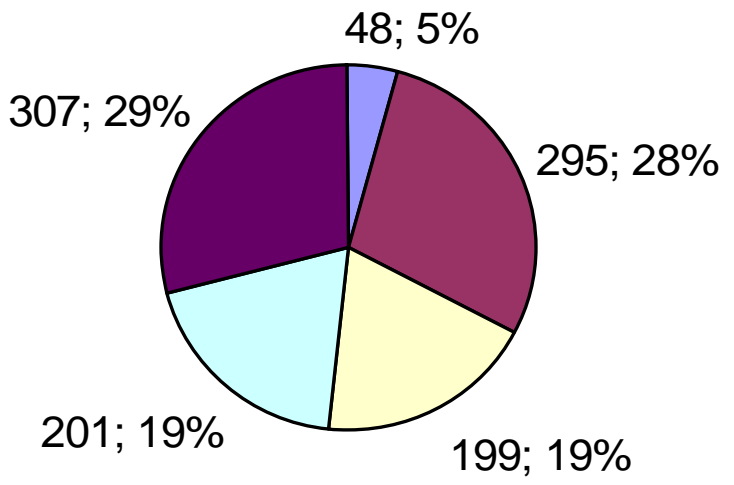

$\square$ ótimo
$\square$ bom
$\square$ regular
$\square$ ruim
$\square$ péssimo

$199 ; 19 \%$ 


\section{SISTEMA DE INFORMAÇÕES}

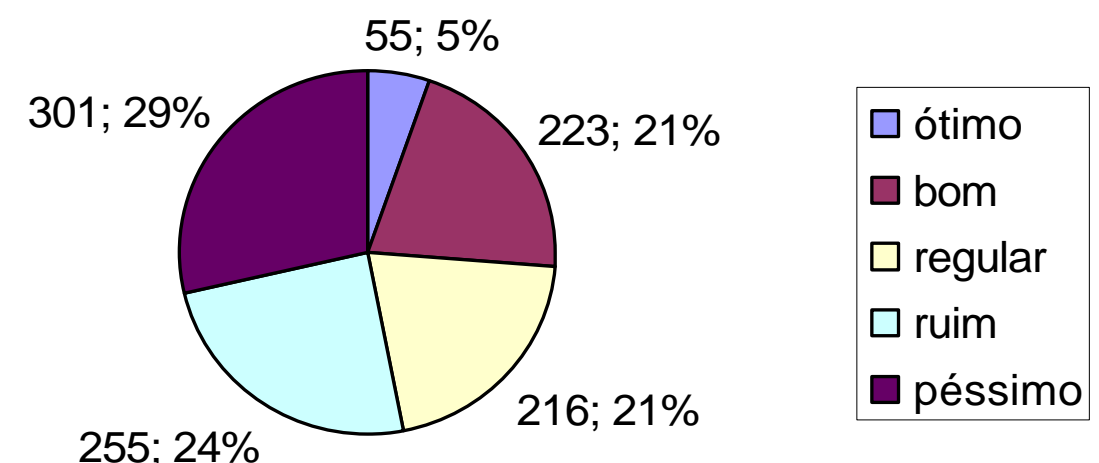

$255 ; 24 \%$

$216 ; 21 \%$ 


\section{COMPORTAMENTO DO OPERADORES}
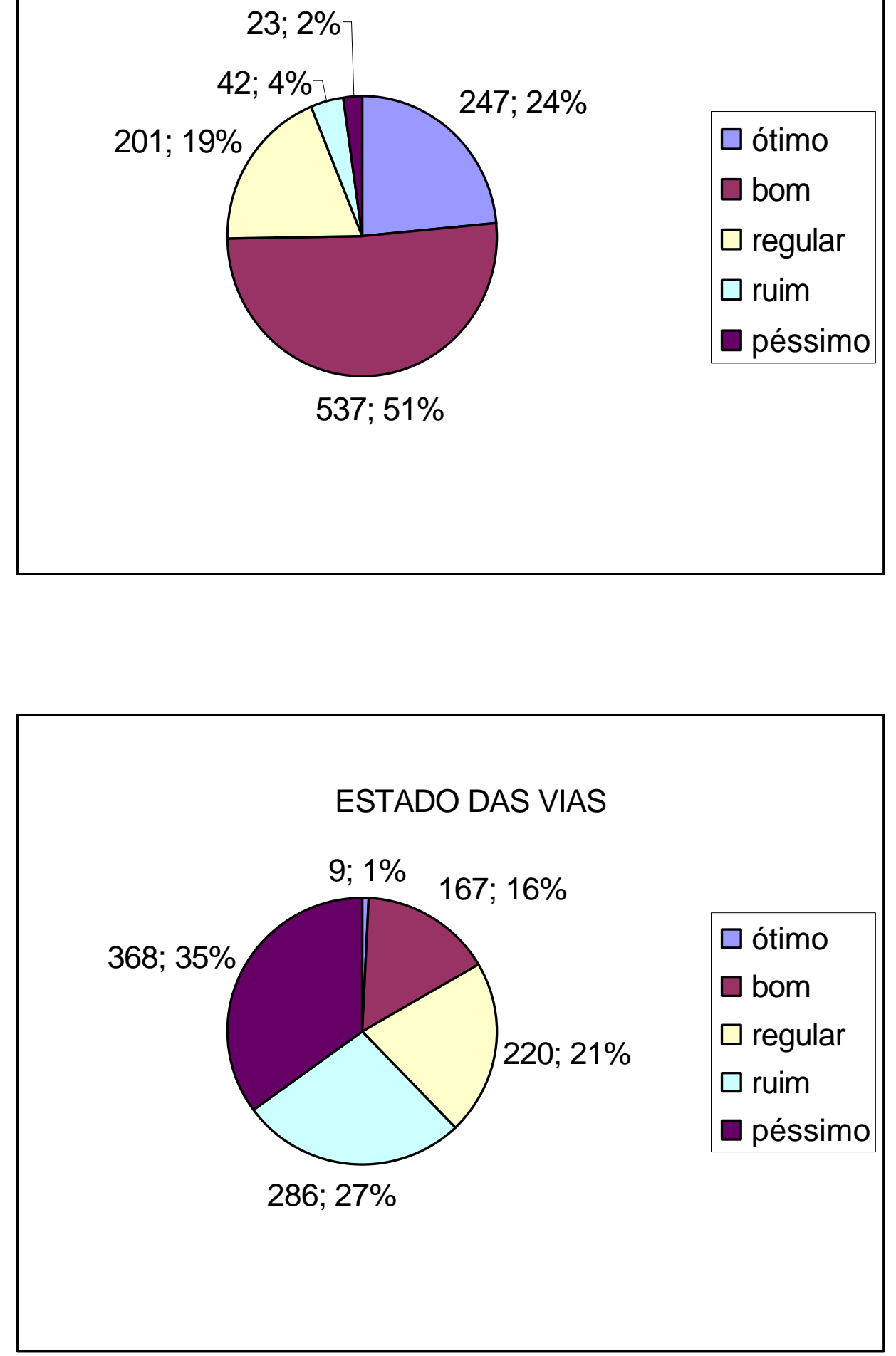